
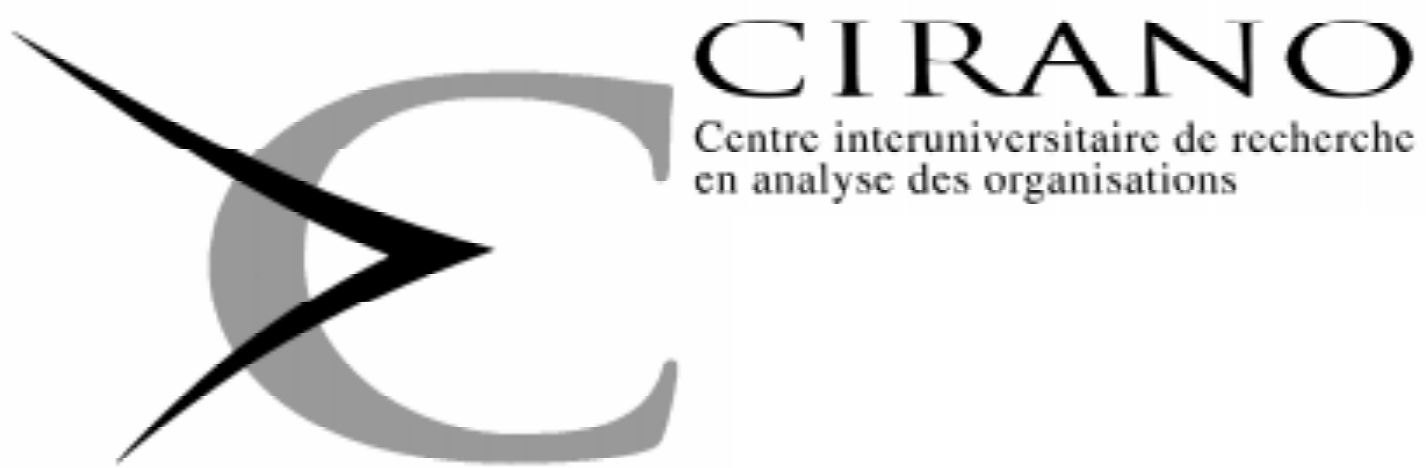
Centre interuniversitaire de recherche en analyse des organisations

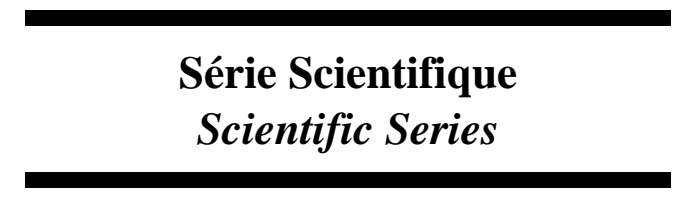

96s-15

\title{
American Options on \\ Dividend-Paying Assets
}

Mark Broadie, Jérôme Detemple

\author{
Montréal \\ mars 1996
}

Typeset by $\mathcal{A M}_{\mathcal{M}} \mathcal{S}-\mathrm{T}_{\mathrm{E}} \mathrm{X}$ 


\section{CIRANO}

Le CIRANO est une corporation privée à but non lucratif constituée en vertu de la Loi des compagnies du Québec. Le financement de son infrastructure et de ses activités de recherche provient des cotisations de ses organisations-membres, d'une subvention d'infrastructure du ministère de l'Industrie, du Commerce, de la Science et de la Technologie, de même que des subventions et mandats obtenus par ses équipes de recherche. La Série Scientifique est la réalisation d'une des missions que s'est données le CIRANO, soit de développer l'analyse scientifique des organisations et des comportements stratégiques.

CIRANO is a private non-profit organization incorporated under the Québec Companies Act. Its infrastructure and research activities are funded through fees paid by member organizations, an infrastructure grant from the Ministère de l'Industrie, du Commerce, de la Science et de la Technologie, and grants and research mandates obtained by its research teams. The Scientific Series fulfils one of the missions of CIRANO: to develop the scientific analysis of organizations and strategic behaviour.

\section{Les organisations-partenaires / The Partner Organizations}

-Ministère de l'Industrie, du Commerce, de la Science et de la Technologie.

-École des Hautes Études Commerciales.

-École Polytechnique.

-Université de Montréal.

-Université Laval.

-McGill University.

-Université du Québec à Montréal.

-Bell Québec.

-La Caisse de dépôt et de placement du Québec.

-Hydro-Québec.

-Fédération des caisses populaires de Montréal et de l'Ouest-du-Québec.

-Téléglobe Canada.

-Société d'électrolyse et de chimie Alcan Ltée.

-Avenor.

-Service de développement économique de la ville de Montréal.

-Raymond, Chabot, Martin, Paré

-Banque Nationale du Canada

Ce document est publié dans l'intention de rendre accessibles les résultats préliminaires de la recherche effectuée au CIRANO, afin de susciter des échanges et des suggestions. Les idées et les opinions émises sont sous l'unique responsabilité des auteurs, et ne représentent pas nécessairement les positions du CIRANO ou de ses partenaires.

This paper presents preliminary research carried out at CIRANO and aims to encourage discussion and comment. The observations and viewpoints expressed are the sole responsibility of the authors. They do not necessarily represent positions of CIRANO or its partners.

ISSN 1198-8177 


\title{
American Options on Dividend-Paying Assets
}

\author{
Mark Broadie ${ }^{\dagger}$, Jérôme Detemple
}

Résumé / Abstract

\section{Résumé :}

Nous présentons un traitement compréhensif de l'évaluation des options Américaines sur des actifs qui payent des dividendes. Nous passons tout d'abord en revue les principes d'évaluation de titres contingents Européens dans le cadre d'un marché financier dans lequel le prix des actifs sous-jacents suivent des processus d'Itô et le taux d'intérêt est stochastique. L'analyse est ensuite généralisée à l'évaluation des titres contingents Américains. Nous présentons, en particulier, les représentations de prime d'exercice prématuré et de prime d'exercice délayé, du prix de l'option Américaine. Ces résultats sont spécialisés au cas du modèle de marché standard, c'est à dire lorsque le prix de l'actif sous-jacent suit un mouvement Borwnien géométrique et le taux d'intérêt est constant. Les options Américaines plafonnées, avec plafond constant ou croissant, sont ensuite analysées. Des formules d'évaluation sont tout d'abord présentées pour les options plafonnées sur des actifs à dividendes dans le contexte du modèle standard. Des résultats nouveaux sont ensuite présentés pour les options plafonnées sur des actifs sans dividende lorsque le prix du sous-jacent suit un processus d'Itô à volatilité stochastique et le taux de croissance du plafond est un processus stochastique adapté.

Mots Clés : $\quad$ Options Américaines, exercice optimal, prime d'exercice, principes d'évaluation, dividendes, options plafonnées, volatilité stochastique, taux d'intérêt stochastique

${ }^{\dagger}$ Graduate School of Business, Colombia University

${ }^{\ddagger}$ Faculty of Management, McGill University and CIRANO 


\begin{abstract}
:
We provide a comprehensive treatement of option pricing with particular emphasis on the valuation of American options on dividend-paying assets. We begin by reviewing valuation principles for European contingent claims in a financial market in which the underlying asset price follows an Itô process and the interest rate is stochastic. Then this analysis is extended to the valuation of American contingent claims. In particular, the early exercise premium and the delayed exercise premium representations of the American option price are presented. These results are specialized in the case of the standard market model, i.e., when the underlying asset price follows a geometric Brownian motion process and the interest rate is constant. American capped options with constant and growing caps are then analyzed. Valuation formulas are first provided for capped options on dividend-paying assets in the context of the standard market model. Previously unpublished results are then presented for capped options on nodividend-paying assets when the underlying asset price follows an Itô process with stochastic volatility and the cap's growth rate is an adapted stochastic process.
\end{abstract}

Keywords : $\quad$ American Options, Optimal Exercise, Exercise Premium, Valuation Principles, Dividends, Capped Options, Stochastic Volatility, Stochastic Interest Rate 


\section{American Options on Dividend-Paying Assets}

\subsection{INTRODUCTION}

Contingent claims such as derivative securities are not new financial instruments. Contracts of this type have indeed been exchanged for several centuries among economic agents. These securities have, however, experienced unprecedented growth in the past twenty years or so, since the creation of the first organized options market, the Chicago Board of Options Exchange (CBOE). Since the opening of this market, the number and the types of options contracts have substantially increased. Today investors can trade foreign exchange options, futures contracts, index options, and bond options in organized markets. Additionally, theoretical and technological progress in the past ten years has made it possible to engineer contracts with new provisions designed to meet specific investment needs. Capped options, Asian options, shout options, and other types of exotic securities can now be purchased in the over-the-counter market or can be issued by firms with specific financing needs.

The valuation of derivative securities has been the object of a long quest. A model describing the random behavior of speculative asset prices was initially proposed by [Bachelier [1900]]. The development of a rigorous theory of option pricing, however, only dates back to the 1970's. [Black and Scholes [1973]] proposed a valuation formula for European options which is consistent with the absence of arbitrage opportunities in the financial market. This model and the underlying methodology are refined and extended by [Merton [1973]]. An equivalent approach based on an appropriately chosen "risk neutral" valuation operator was pioneered by [Cox and Ross [1976]]. The foundations and principles underlying these valuation methods are identified and characterized in the seminal paper by [Harrison and Kreps [1979]].

The valuation of American options also has a long history. [Samuelson [1965]] and [McKean [1965]] initially treat this problem as a stopping time problem unrelated to the pricing measure embedded in the underlying asset prices. It is only recently, however, that the optimal stopping problem has been posed relative to an appropriate measure which correctly prices American options ([Bensoussan [1984]] and [Karatzas [1988]]). [Karatzas [1988]], in particular, shows that the American option payoff can be replicated by a carefully chosen strategy of investment in the primary assets in the model. The value of the American option, then, must equal the value of the replicating portfolio to avoid arbitrage opportunities and be consistent with economic equilibrium.

While the stopping time approach to American option valuation is instructive, it does not provide much insight into the properties of the 
optimal exercise boundary, nor does it lead to efficient numerical procedures. [Kim [1990]], [Jacka [1991]] and [Carr, Jarrow and Myneni [1992]] derive, in the context of the standard market model (geometric Brownian motion for the underlying asset price and a constant interest rate), an early exercise premium representation of the value of the American option. This representation expresses the value of the American option as the corresponding European option value plus the gains from early exercise. The gains from early exercise are the present value of the dividend benefits in the exercise region net of the interest losses on the payments incurred upon exercise.

In fact, the early exercise premium formula is the Riesz decomposition of the Snell envelope which arises in the stopping time problem associated with the valuation of the option contract. The Riesz decomposition was initially proved in the context of stopping time problems by [El Karoui and Karatzas [1991]]. [Myneni [1992]] adapts their results to the American put pricing problem in the context of the standard market model. The decomposition was recently extended to a fairly general class of market models with semimartingale price processes by [Rutkowski [1994]].

The early exercise premium representation is written in terms of the optimal exercise boundary. By imposing a boundary condition, this representation can be used to derive a recursive integral equation for the optimal exercise boundary. This equation can be used in a numerical procedure to solve for the optimal exercise boundary which determines the value of the American option.

While the valuation of standard American option contracts has now achieved a fair degree of maturity, much work remains to be done regarding the new contractual forms that are constantly emerging in response to new economic conditions and regulations. One innovation which has received some attention is the class of capped option contracts. These are options with a ceiling on their payoff (or a floor for put options) which limits the potential gains from early exercise. These options are attractive from the perspective of issuers since they limit their potential liabilities, yet they retain some attractiveness for purchasers since they provide upside potential and are less costly than their uncapped counterpart. As a result, such options have appeared as components of securities issued by firms to cover certain financing needs. A recent treatment of these options, in the context of the standard market model, appears in [Broadie and Detemple [1995]].

In this paper we provide a comprehensive treatment of option pricing with particular emphasis on the valuation of American options on dividend-paying assets. In the second section we review valuation principles for European contingent claims in a financial market in which the 
underlying asset price follows an Itô process and the interest rate is stochastic. In Section 1.3 the analysis is extended to American contingent claims. In this context we review the basic valuation principle for American options. We also provide two representation formulas, the early exercise premium and the delayed exercise premium representations, which are based on recent developments in the field. These results are then applied in Section 1.4 to American option valuation in the context of the standard market model, i.e., when the underlying asset price follows a geometric Brownian motion process and the interest rate is constant. American capped options with constant and growing caps are analyzed in Section 1.5. Valuation formulas are first provided for capped options on dividend-paying assets in the context of the standard market model. Previously unpublished results are then presented for capped options on nondividend-paying assets when the underlying asset price follows an Itô process with stochastic volatility and the cap's growth rate is an adapted stochastic process.

\subsection{The Valuation of European Contingent Claims}

We first define the classes of contingent claims which are the focus of our analysis (subsection 1.2.1). We proceed with a description of the economic setting (subsection 1.2.2). Attainable European contingent claims are then characterized (subsection 1.2.3) and valued (subsection 1.2.4).

\subsubsection{Definitions.}

A derivative security is a financial contract whose payoff depends on the price(s) of some underlying or primary asset(s). In their most general form, derivative securities generate a flow of payments over periods of time as well as cash payments at specific dates. In addition, the cash flows need not be paid at fixed points in time or during fixed periods of time. Some derivative securities involve cash flows paid at prespecified random times or even at (random) times which are chosen by the holder of the contract.

The standard example of a derivative security is an option contract. An option gives the holder of the contract the right, but not the obligation, to buy (or sell) a given asset, at a predetermined price (the exercise or strike price), at or before some prespecified future date (the maturity date). The option to buy (sell) is a call (put) option. A European option contract can be exercised at the fixed maturity date $T$ only. Since exercise at maturity is only optimal if the option is in the money, the payoff on a European call option written on a stock equals $\left(S_{T}-K\right)^{+}$, where $S_{T}$ is the price of the underlying stock (primary asset) at the specified maturity date and $K>0$ is the exercise price of the contract. An American option 
contract can be exercised at any time at or before the maturity date.

\subsubsection{The Economy.}

We consider an economy with the following characteristics. The uncertainty is represented by a complete probability space $(\Omega, \mathcal{F}, P)$ where $\Omega$ is the set of elementary events or "states of nature" with generic element $\omega, \mathcal{F}$ is a $\sigma$-algebra representing the collection of observable events and $P$ is a probability measure defined on $(\Omega, \mathcal{F})$. The time period is the finite interval $[0, T]$. A Brownian motion process $z$ is defined on $(\Omega, \mathcal{F}, P)$ with values in the real numbers $\mathbf{R}$. The flow of information is given by the natural filtration $\left\{\mathcal{F}_{t}\right\}$, i.e. the $P$-augmentation of the Brownian filtration. Without loss of generality we set $\mathcal{F}_{T}=\mathcal{F}$ so that all the observable events are eventually known. Our model for information and beliefs is $\left(\Omega, \mathcal{F},\left\{\mathcal{F}_{t}, t \in[0, T]\right\}, P\right)$.

Two types of financial securities are traded in the asset market: a riskless asset (bond) and a risky asset (stock). The price of the riskless asset, $B$, satisfies the equation

$$
d B_{t}=r_{t} B_{t} d t, t \in[0, T], B_{0} \text { given, }
$$

where $r=\left\{r_{t}, \mathcal{F}_{t}: t \in[0, T]\right\}$ is a bounded, strictly positive and progressively measurable process of the filtration which represents the interest rate in the economy. For notational convenience, define the discount factor $R_{s, t}=\exp \left(-\int_{s}^{t} r_{v} d v\right)$.

The price of the stock satisfies the stochastic differential equation

$$
d S_{t}=S_{t}\left[\left(\mu_{t}-\delta_{t}\right) d t+\sigma_{t} d z_{t}\right], t \in[0, T], S_{0} \text { given }
$$

The process $\delta \equiv\left\{\delta_{t}, \mathcal{F}_{t}: t \in[0, T]\right\}$ represents the dividend rate on the stock; $\mu \equiv\left\{\mu_{t}, \mathcal{F}_{t}: t \in[0, T]\right\}$ and $\sigma \equiv\left\{\sigma_{t}, \mathcal{F}_{t}: t \in[0, T]\right\}$ are the drift and the volatility coefficients of the stock's total rate of return, respectively. The coefficients $\delta, \mu$, and $\sigma$ are bounded and progressively measurable processes of the filtration. The dividend rate is nonnegative, $\delta \geq 0$; the volatility $\sigma$ is bounded above and bounded away from zero (P-a.s.), i.e., the financial market under consideration is complete.

Remark 1.2.1. The financial market is complete when a relevant class of state contingent claims, i.e., cash flows that depend on the realized trajectories of the Brownian motion process $z$, can be attained by an appropriate portfolio of available financial assets. When the volatility coefficient $\sigma$ is bounded away from zero, the stochastic shocks affecting the financial market (the Brownian motion $z$ ) can be hedged away, at all times, by investing in the stock. The ability to design unconstrained investment 
strategies in the stock and in the bond, then, ensures the attainability of these contingent claims ([Harrison and Kreps [1979]], [Harrison and Pliska [1981]], [Duffie [1986]]).

It has become standard to use stochastic processes of the form (1.2.2) to model the behavior of stock prices. For instance, the geometric Brownian motion process which is obtained by taking constant coefficients $(\mu, \sigma, \delta)$, is used as a basis for the [Black and Scholes [1973]] analysis. Alternative formulations which have received attention include some processes with jumps ([Merton [1973]], [Cox and Ross [1976]]).

In order to determine the prices of contingent claims we start by characterizing the set of random variables (payoffs) that can be generated by trading strategies involving only the stock and the bond.

Let $X$ denote the wealth process generated by an investment strategy in the financial assets (1.2.1)-(1.2.2). We first define the set of "allowable" or "admissible" consumption-investment strategies. A portfolio process $\pi=\left\{\pi_{t}, \mathcal{F}_{t}: t \in[0, T]\right\}$ is a progressively measurable, $\mathbf{R}$-valued process such that $\int_{0}^{T} \pi_{t} d t<\infty$, (P-a.s.). Here $\pi_{t}$ denotes the (dollar) investment in the stock at date $t$; the amount invested in the bond contract is $X_{t}-\pi_{t}$. A cumulative consumption process $C=\left\{C_{t}, \mathcal{F}_{t}: t \in[0, T]\right\}$ is a progressively measurable, nondecreasing, right-continuous process with values in $\mathbf{R}$ and initial value $C_{0}=0$. Since we consider nondecreasing cumulative consumption processes only, the portfolio processes under consideration allow for withdrawal of funds (for consumption purposes). When cumulative consumption is null at all times the portfolio is said to be self-financing: it involves neither infusions nor withdrawals of funds but only rebalancing of the existing positions held in the different assets.

An investment of $\pi_{t}$ in the stock at date $t$ produces a total return (capital gains plus dividends) equal to $\pi_{t}\left[\left(d S_{t} / S_{t}\right)+\delta_{t} d t\right]$. An investment of $X_{t}-\pi_{t}$ in the bond has a return of $\left(X_{t}-\pi_{t}\right) r_{t} d t$. The activity of consumption reduces wealth by the corresponding amount $d C_{t}$. Hence, a consumption-portfolio strategy $(C, \pi)$ generates the wealth process $X$ which solves the stochastic differential equation

$$
\begin{aligned}
d X_{t} & =\left(X_{t}-\pi_{t}\right) r_{t} d t+\pi_{t}\left[\left(d S_{t} / S_{t}\right)+\delta_{t} d t\right]-d C_{t}, t \in[0, T] ; X_{0}=x, \\
& =r_{t} X_{t} d t+\pi_{t}\left(\mu_{t}-r_{t}\right) d t+\pi_{t} \sigma_{t} d z_{t}-d C_{t}, t \in[0, T] ; X_{0}=x
\end{aligned}
$$

Given an initial investment $x>0$, a consumption-portfolio strategy $(C, \pi)$ is admissible, if the associated wealth process $X$ solving (1.2.3) satisfies the nonnegativity constraint

$$
X_{t} \geq 0, \quad t \in[0, T] \quad(\text { P-a.s. })
$$


This condition is a no-bankruptcy condition which stipulates that wealth cannot be negative during the trading period. Let $\mathcal{A}(x)$ denote the set of admissible strategies.

A European contingent claim $(f, Y)$ is composed of a cumulative payment process $f \equiv\left\{f_{t}, \mathcal{F}_{t}: t \in[0, T]\right\}$ which is nondecreasing, progressively measurable, right-continuous and null at zero, and a nonnegative $\mathcal{F}_{t}$-measurable cash flow $Y$ at date $T$.

A consumption-portfolio strategy $(C, \pi)$ generates a European contingent claim $(f, Y)$ if $(C, \pi)$ is admissible, $C_{t}=f_{t}$, and $X_{T}=Y$. The claim $(f, Y)$ is attainable from an initial investment $x$ if there exists an admissible consumption-portfolio strategy such that $C_{t} \geq f_{t}$ for all $t \in[0, T]$ and $X_{T} \geq Y$ (P-a.s.).

\subsubsection{Attainable Contingent Claims.}

The pricing of contingent claims amounts to the identification of an appropriate valuation operator which maps future payoffs into current prices. Since the processes satisfying (1.2.1) and (1.2.2) represent the prices of traded assets, this valuation operator must be consistent with these prices. In fact, as will become clear below, the price processes (1.2.1)-(1.2.2) completely determine the valuation operator in this economy.

The market model (1.2.1) and (1.2.2) implies a unique market price per unit risk $\theta \equiv\left\{\theta_{t}, \mathcal{F}_{t}: t \in[0, T]\right\}$ equal to $\theta_{t}=\sigma_{t}^{-1}\left(\mu_{t}-r_{t}\right)$. This onedimensional process is well defined, progressively measurable and bounded since $\sigma$ is bounded away from zero; it is uniquely defined because of market completeness. The market price of risk represents the excess expected return implicitly assigned by the model (1.2.1)-(1.2.2) to the stochastic shocks $z$ affecting the financial market.

Consider now the exponential process $\eta \equiv\left\{\eta_{t}, \mathcal{F}_{t}: t \in[0, T]\right\}$ defined by

$$
\eta_{t}=e^{-\left(\int_{0}^{t} \theta_{s} d z_{s}+\frac{1}{2} \int_{0}^{t} \theta_{s}^{2} d s\right)}
$$

Boundedness of the market price of risk implies that the Novikov condition is satisfied; it follows that $\eta$ is a martingale ([Karatzas and Shreve [1988, Chapter 3, Corollary 5.13]]). We can then define the equivalent martingale probability measure, $Q(A)=E\left[\eta_{T} \mathbf{1}_{A}\right], A \in \mathcal{F}_{T}$. That is, $Q$ is equivalent to $P$ and is unique due to the completeness of the financial market. Additionally, by the Girsanov Theorem ([Karatzas and Shreve [1988, Chapter 3, Theorem 5.1]]) the process $\tilde{z}_{t}=z_{t}+\int_{0}^{t} \theta_{s} d s$, for $t \in[0, T]$, is a standard $Q$-Brownian motion process.

Under the equivalent martingale measure $Q$, the ex-dividend price process $R_{0, t} S_{t}$ is a $Q$-supermartingale (recall $R_{s, t} \equiv \exp \left(-\int_{s}^{t} r_{v} d v\right)$ ). The 
process consisting of the discounted ex-dividend price augmented by the discounted dividends, $S_{t}^{*} \equiv R_{0, t} S_{t}+\int_{0}^{t} R_{0, v} \delta_{v} S_{v} d v$, is a $Q$-martingale. It satisfies the equation

$$
d S_{t}^{*}=S_{t}^{*} \sigma_{t} d \tilde{z}_{t}, t \in[0, T] ; S_{0}^{*}=S_{0} .
$$

We conclude that the present value formula

$$
S_{t}=E^{*}\left[R_{t, T} S_{T}+\int_{t}^{T} R_{t, v} \delta_{v} S_{v} d v \mid \mathcal{F}_{t}\right]
$$

holds, where $E^{*}$ denotes the expectation relative to the measure $Q$. In this formula the discount rate is locally riskless (conditional on contemporaneous information) but risky relative to the information available strictly prior to current time. Hence the discount factor $R_{t, T}$ is an $\mathcal{F}_{T}$-measurable random variable which cannot be factored out of the expectation operator $E^{*}\left[\cdot \mid \mathcal{F}_{t}\right]$. Finally, we note that the system of Arrow-Debreu prices implied by the price system (1.2.1)-(1.2.2) is given by $R_{0, t} \eta_{t} d P$ : these prices represent the value attributed by the market at date 0 to one dollar paid in state $(t, \omega)$. The state price density is defined as $\xi_{t} \equiv R_{0, t} \eta_{t}$.

Consider European contingent claims $(f, Y)$ which satisfy the integrability condition

$$
E\left[\xi_{T} Y\right]+E\left[\int_{0}^{T} \xi_{s} d f_{s}\right]<\infty
$$

Let $I$ denote this class of claims.

Our first theorem provides a characterization of the set of attainable contingent claims.

Theorem 1.2.2. Consider a contingent claim $(f, Y) \in I$. If $(f, Y)$ is attainable at date $T$ from an initial investment $x$ then

$$
E^{*}\left[R_{0, T} Y\right]+E^{*}\left[\int_{0}^{T} R_{0, s} d f_{s}\right] \leq x .
$$

Equivalently, if $(f, Y)$ is attainable from $x$ then

$$
E\left[\eta_{t} R_{0, T} Y\right]+E\left[\int_{0}^{T} \eta_{s} R_{0, s} d f_{s}\right] \leq x
$$

where the expectation is taken relative to the measure $P$. Conversely, suppose that (1.2.9) holds. Then there exists an admissible consumptionportfolio strategy $(C, \pi)$ such that $(f, Y)$ is attainable from the initial wealth $x$.

In proposition 1.2.6 below we show that $E^{*}\left[R_{0, T} Y\right]+E^{*}\left[\int_{0}^{T} R_{0, s} d f_{s}\right]$ represents the present value at date 0 of the contingent claim $(f, Y)$. 
Hence, the condition (1.2.9) states that the present value of the contingent claim $(f, Y)$ is less than or equal to the value of initial wealth $x$ which attains the claim.

Proof of Theorem 1.2.2. (i) Necessity: consider an admissible policy $(C, \pi) \in$ $\mathcal{A}(x)$. The associated wealth process corresponding to an initial investment $x$ is the solution to equation (1.2.3) given by

$$
X_{t}=R_{0, t}^{-1}\left(x-\int_{0}^{t} R_{0, s} d C_{s}+\int_{0}^{t} R_{0, s} \pi_{1 s}\left(\mu_{s}-r_{s}\right) d s+\int_{0}^{t} R_{0, s} \pi_{1 s} \sigma_{s} d z_{s}\right)
$$

for all $t \in[0, T]$. Equivalently, using the definition of the process $\tilde{z}$,

$$
X_{t} R_{0, t}+\int_{0}^{t} R_{0, s} d C_{s}=x+\int_{0}^{t} R_{0, s} \pi_{1 s} \sigma_{s} d \tilde{z}_{s} .
$$

The righthand side of (1.2.11) is a continuous $Q$-local martingale. Admissibility of $(C, \pi)$ implies that the lefthand side of (1.2.11) is nonnegative. The combination of these two properties implies that the righthand side is a nonnegative $Q$-supermartingale ([Karatzas and Shreve [1988, Chapter 1, Problem 5.19]]). Taking expectations on both sides of (1.2.11) and setting $t=T$ yields

$$
E^{*}\left[R_{0, T} X_{T}\right]+E^{*}\left[\int_{0}^{T} R_{0, s} d C_{s}\right] \leq x .
$$

Hence if $(f, Y)$ is attainable $\left(X_{T} \geq Y\right.$ and $C_{t} \geq f_{t}$ for all $\left.t \in[0, T]\right)$ from initial wealth $x$ then

$$
E^{*}\left[R_{0, T} Y\right]+E^{*}\left[\int_{0}^{T} R_{0, s} d f_{s}\right] \leq E^{*}\left[R_{0, T} X_{T}\right]+E^{*}\left[\int_{0}^{T} R_{0, s} d C_{s}\right]=x
$$

and (1.2.9) follows.

(ii) Sufficiency: conversely, suppose that $(f, Y) \in I$ satisfies equation (1.2.9). By the fundamental representation theorem for Brownian martingales ([Karatzas and Shreve [1988, Chapter 3, Theorem 4.15]]) the $P$ martingale $M_{t}$ defined by $E\left[\eta_{T} R_{0, T} Y \mid \mathcal{F}_{t}\right]+E\left[\eta_{T} \int_{0}^{T} R_{0, s} d f_{s} \mid \mathcal{F}_{t}\right]$ has the representation

$$
M_{t}=M_{0}+\int_{0}^{t} \phi_{s} d z_{s}
$$

where $\phi \equiv\left\{\phi_{t}, \mathcal{F}_{t}: t \in[0, T]\right\}$ is a one-dimensional, $\mathcal{F}_{t}$-progressively measurable process such that $\int_{0}^{T} \phi_{t}^{2} d t<\infty$ (P-a.s.). An application of Bayes' 
law shows that the $Q$-martingale $M_{t}^{*} \equiv E^{*}\left[R_{0, T} Y \mid \mathcal{F}_{t}\right]+E^{*}\left[\int_{0}^{T} R_{0, s} d f_{s} \mid \mathcal{F}_{t}\right]$ equals

$$
M_{t}^{*}=\eta_{t}^{-1} M_{t}
$$

Using (1.2.5), (1.2.14), and applying Itô's lemma leads to $M_{t}^{*}=M_{0}^{*}+$ $\int_{0}^{t} \phi_{s}^{*} d \tilde{z}_{s}$, where $\phi_{t}^{*} \equiv \eta_{t}^{-1}\left(\phi_{t}+M_{t} \theta_{t}\right)$ and $\tilde{z}$ is the $Q$-Brownian motion process defined earlier. Selecting the portfolio process $\pi_{t}=R_{0, t}^{-1} \sigma_{t}^{-1} \phi_{t}^{*}$ and replacing in the wealth process $X$ of equation (1.2.11) yields

$$
\begin{aligned}
R_{0, t} X_{t} & +\int_{0}^{t} R_{0, s} d C_{s}=x+\int_{0}^{t} \phi_{s}^{*} d \tilde{z}_{s} \\
& =x-E^{*}\left[R_{0, T} Y+\int_{0}^{T} R_{0, s} d f_{s}\right]+E^{*}\left[R_{0, T} Y+\int_{0}^{T} R_{0, s} d f_{s} \mid \mathcal{F}_{t}\right],
\end{aligned}
$$

for $t \in[0, T]$. At time $T$ we get $R_{0, T} X_{T}+\int_{0}^{T} R_{0, s} d C_{s}=x-E^{*}\left[R_{0, T} Y+\right.$ $\left.\int_{0}^{T} R_{0, s} d f_{s}\right]+\left(R_{0, T} Y+\int_{0}^{T} R_{0, s} d f_{s}\right)$ since $R_{0, T} Y+\int_{0}^{T} R_{0, s} d f_{s}$ is $\mathcal{F}_{T}$-measurable. Condition (1.2.9) then implies $R_{0, T} X_{T}+\int_{0}^{T} R_{0, s} d C_{s} \geq R_{0, T} Y+\int_{0}^{T} R_{0, s} d f_{s}$. Selecting $C=f$ yields $X_{T} \geq Y$. Furthermore $X_{T}=Y$ (P-a.s.) if (1.2.9) holds with equality.

Remark 1.2.3. As shown in the sufficiency part of Theorem 1.2.2, the wealth process associated with the consumption-portfolio strategy $(C, \pi)$ that generates $(f, Y)$ is

$$
X_{t}=E^{*}\left[R_{t, T} Y+\int_{t}^{T} R_{t, s} d f_{s} \mid \mathcal{F}_{s}\right], \quad t \in[0, T]
$$

Hence the wealth process is nonnegative at all times, since $f$ and $Y$ are nonnegative. The wealth process equals the present value of the future cash flows generated by the policy $(C, \pi)$.

\subsubsection{The Valuation of Attainable Contingent Claims.}

Given our characterization of attainable contingent claims in Theorem 1.2.2 it is now easy to deduce their market value. To this end, we define the notion of an arbitrage opportunity and the rational price of a contingent claim.

Definition 1.2.4. A consumption-portfolio strategy $(C, \pi)$ is an arbitrage opportunity if $(C, \pi) \in \mathcal{A}(0), P\left(X_{T} \geq 0\right)=1$, and $P\left(X_{T}>0\right)>0$.

An arbitrage opportunity is a consumption-portfolio strategy which has zero initial cost, requires no intermediate cash infusions, and has a strictly positive probability of positive wealth at time $T$ (and zero probability of negative wealth). 
Definition 1.2.5. The rational price of the claim $(f, Y)$ is the price which is consistent with the absence of arbitrage opportunities in the financial market.

The rational price of the contingent claim $(f, Y)$ is also called the market value of the claim. Indeed, deviations of the market price from the rational price would lead to infinite demand for the arbitrage portfolio. This situation is inconsistent with an equilibrium in the financial market at these prices. Since the financial market is complete, the rational price of an attainable contingent claim is unique. We are now ready to provide a valuation formula for the contingent claim.

Proposition 1.2.6. The rational price at time $t$ of the European contingent claim $(f, Y) \in I$ is uniquely given by

$$
V_{t}(f, Y)=E^{*}\left[R_{t, T} Y \mid \mathcal{F}_{t}\right]+E^{*}\left[\int_{t}^{T} R_{t, s} d f_{s} \mid \mathcal{F}_{t}\right]
$$

for $t \in[0, T]$.

Proof of Proposition 1.2.6. The contingent claim $(f, Y)$ is attainable from all initial investments $x$ satisfying the budget constraint (1.2.9). Minimizing over this set yields the (unique) minimum investment from which $(f, Y)$ is attainable: $x^{*}=E^{*}\left[R_{0, T} Y\right]+E^{*}\left[\int_{0}^{T} R_{0, s} d f_{s}\right]$. The rational price of $Y$ at date zero must then equal $V_{0}(f, Y)=x^{*}$ for otherwise an arbitrage opportunity exists. Since the sum of discounted wealth plus cumulative discounted dividends is a $Q$-martingale, similar reasoning establishes that the minimum amount of wealth that must be invested at date $t$ to generate $(f, Y)$ is $X_{t}=E^{*}\left[R_{t, T} Y \mid \mathcal{F}_{t}\right]+E^{*}\left[\int_{t}^{T} R_{t, s} d f_{s} \mid \mathcal{F}_{t}\right]$. The price of the claim at date $t$ follows.

Proposition 1.2.6 provides our most general pricing formula in the context of the Itô financial market model (1.2.1)-(1.2.2). It states that the value of any European contingent claim involving cash flow payments over $[0, T]$ is simply the expected value of the discounted cash flows. Here discounting is made at the locally riskfree interest rate whereas the expectation is taken under the equivalent martingale measure implicit in the market model (1.2.1)-(1.2.2). Note that this present value formula is valid even though the riskfree rate as well as the drift and volatility of the stock price process are progressively measurable processes of the Brownian filtration, i.e., even though they may depend on the history of the Brownian motion. If the market price of the contingent claim ever deviates from the rational price prescribed by the formula, it is possible to construct a portfolio of the claim, the stock, and the bond, and a trading strategy which represents an arbitrage opportunity. 
Standard European option contracts involve a payment at the maturity date $T$ only. For a call option the cumulative payment flow is $f=0$ and the terminal payoff is $Y=\left(S_{T}-K\right)^{+}$; for a put option $f=0$ and $Y=\left(K-S_{T}\right)^{+}$. In these cases the pricing formula $V_{t}(f, Y)$ specializes as follows.

Corollary 1.2.7. In the financial market model (1.2.1)-(1.2.2) the rational price of a European call option with maturity date $T$ and exercise price $K$ is given by $C_{t}=E^{*}\left[R_{t, T}\left(S_{T}-K\right)^{+} \mid \mathcal{F}_{t}\right]$, for $t \in[0, T]$. The price of a European put option is $P_{t}=E^{*}\left[R_{t, T}\left(K-S_{T}\right)^{+} \mid \mathcal{F}_{t}\right]$, for $t \in[0, T]$.

When the interest rate is constant, the price of an option written on a nondividend-paying stock whose price follows a geometric Brownian motion process satisfies the [Black and Scholes [1973]] formula (see also [Merton [1973]]).

Corollary 1.2.8. ([Black and Scholes [1973]]) Suppose that the interest rate $r$ is constant and that the stock price follows a geometric Brownian motion process without dividends $((\mu, \sigma)$ constants, $\delta=0)$. Then the price of a European call option simplifies to

$$
C_{t}=S_{t} N(d)-e^{-r \tau} K N(d-\sigma \sqrt{\tau})
$$

where $\tau \equiv T-t$ is the time to maturity, $N(\cdot)$ is the cumulative standard normal distribution function, and $d \equiv(\sigma \sqrt{\tau})^{-1}\left(\log \left(S_{t} / K\right)+\left(r+\frac{1}{2} \sigma^{2}\right) \tau\right)$. The price of the associated European put option with same maturity and exercise price is obtained from the put-call parity relationship: $P_{t}=C_{t}-$ $S_{t}+e^{-r \tau} K$.

Proof of Corollary 1.2.8. Under the conditions stated, Proposition 1.2.6 shows that the option price is given by $C_{t}=e^{-r \tau} E^{*}\left[\left(S_{T}-K\right)^{+} \mid \mathcal{F}_{t}\right]$. Define the exercise region as the set $E \equiv\left\{\omega \in \Omega: S_{T} \geq K\right\}$ of states of nature in which the stock price at date $T$ exceeds the exercise price $K$. Let $\mathbf{1}_{E}$ denote the indicator of $E$. Then the option price simplifies to $C_{t}=e^{-r \tau} E^{*}\left[\mathbf{1}_{E}\left(S_{T}-K\right) \mid \mathcal{F}_{t}\right]=e^{-r \tau}\left(E^{*}\left[\mathbf{1}_{E} S_{T} \mid \mathcal{F}_{t}\right]-K E^{*}\left[\mathbf{1}_{E} \mid \mathcal{F}_{t}\right]\right)$. The second expectation appearing in this expression is simply the $Q$-measure of the set $E$ conditional on the information at date $t$. Under the measure $Q$ the stock price is given by $S_{T}=S_{t} e^{\left(r-\frac{1}{2} \sigma^{2}\right) \tau+\sigma\left(\tilde{z}_{T}-\tilde{z}_{t}\right)}$ where $\tilde{z}_{T}-\tilde{z}_{t}$ is distributionally equivalent to $\tilde{z} \sqrt{T-t}$ where the random variable $\tilde{z}$ follows has a normal distribution with mean zero and unit variance. It follows that

$$
\begin{aligned}
E^{*}\left[\mathbf{1}_{E} \mid \mathcal{F}_{t}\right]=Q\left(E ; \mathcal{F}_{t}\right) & =Q\left(\tilde{z}_{T}-\tilde{z}_{t} \geq \sigma^{-1}\left[\log \left(K / S_{t}\right)-\left(r-\frac{1}{2} \sigma^{2}\right) \tau\right]\right) \\
& =1-N(-d+\sigma \sqrt{\tau})=N(d-\sigma \sqrt{\tau})
\end{aligned}
$$


where $N(\cdot)$ is the cumulative standard normal distribution. The first expectation simplifies to

$$
\begin{aligned}
e^{-r \tau}\left[E^{*}\left[\mathbf{1}_{E} S_{T} \mid \mathcal{F}_{t}\right]\right. & =S_{t} E^{*}\left[\mathbf{1}_{E} e^{-\frac{1}{2} \sigma 2 \tau+\sigma\left(\tilde{z}_{T}-\tilde{z}_{t}\right)} \mid \mathcal{F}_{t}\right] \\
& =S_{t} \int_{-\infty}^{\infty} \mathbf{1}_{E} e^{-\frac{1}{2} \sigma^{2} \tau+\sigma u \sqrt{\tau}} n(u) d u
\end{aligned}
$$

where $n(u)$ is the density of the standard normal. Computing the integral yields formula (1.2.16).

To prove the put-call parity relationship, note that $\left(K-S_{T}\right)^{+}=\left(S_{T}-\right.$ $K)^{+}-S_{T}+K$. No arbitrage implies that the value of the put must equal the value of the portfolio of the securities on the righthand side of the equality. The parity relationship follows.

An explicit formula for the option can also be computed when the coefficients of the model change deterministically over time.

Corollary 1.2.9. (Black-Scholes with deterministic coefficients) Consider the financial market model with deterministic interest rate, drift and volatility coefficients $\left(r_{t}, \mu_{t}, \sigma_{t}\right)$ without dividends $(\delta=0)$. Then, the price of a European call option is given by

$$
C_{t}=S_{t} N(d)-R_{t, T} K N\left(d-\left(\int_{t}^{T} \sigma_{v}^{2} d v\right)^{\frac{1}{2}}\right)
$$

where $N(\cdot)$ is the cumulative standard normal distribution function and

$$
\left.d \equiv\left(\int_{t}^{T} \sigma_{v}^{2} d v\right)^{-\frac{1}{2}}\right)\left[\log \left(S_{t} / K\right)+\int_{t}^{T}\left(r_{v}+\frac{1}{2} \sigma_{v}^{2}\right) d v\right] .
$$

Proof of Corollary 1.2.9. Under the assumptions stated, the stock price $S_{T}$ equals $S_{t} \exp \left(\int_{t}^{T}\left(r_{v}-\frac{1}{2} \sigma_{v}^{2}\right) d v+\int_{t}^{T} \sigma_{v} d \tilde{z}_{v}\right)$. Furthermore the stochastic integral $\int_{t}^{T} \sigma_{v} d \tilde{z}_{v}$ has normal distribution with zero mean and variance $\int_{t}^{T} \sigma_{v}^{2} d v$. Performing the same computations as in the proof of Corollary 1.2.8 yields the result.

The next result provides the price of a European option on a dividendpaying stock in a financial market with deterministic coefficients.

Corollary 1.2.10. (Black-Scholes with dividend adjustment) Consider the financial market model with deterministic interest rate, drift and volatility coefficients, and dividend rate $\left(r_{t}, \mu_{t}, \sigma_{t}, \delta_{t}\right)$, respectively. The price of a European call option is given by

$$
C_{t}=S_{t} D_{t, T} N(d)-R_{t, T} K N\left(d-\left(\int_{t}^{T} \sigma_{v}^{2} d v\right)^{\frac{1}{2}}\right)
$$

where $D_{t, T} \equiv \exp \left(-\int_{t}^{T} \delta_{v} d v\right), N(\cdot)$ is the cumulative standard normal distribution function, and

$$
d \equiv\left(\int_{t}^{T} \sigma_{v}^{2} d v\right)^{-\frac{1}{2}}\left[\log \left(S_{t} / K\right)+\int_{t}^{T}\left(r_{v}-\delta_{v}+\frac{1}{2} \sigma_{v}^{2}\right) d v\right] .
$$




\subsection{American Contingent Claims}

We now turn to the valuation of American contingent claims. These claims can be exercised during certain prespecified periods of time at the option of the holder of the security. To value these contracts we first need to identify the optimal exercise strategy. The absence of arbitrage opportunities implies that the value of the contract is its value under the optimal exercise policy.

In this section we provide three representations of the price of an American contingent claim. The results are used in the next two sections to provide explicit valuation formulas for standard American options and capped American options when the underlying asset price follows a geometric Brownian motion process.

As a preliminary step we extend the valuation formula in Proposition 1.2.6 to securities with payoffs at random times. The economic setting is the one described in subsection 1.2.2.

A random time $\tau$ is a stopping time of the (Brownian) filtration $\left\{\mathcal{F}_{t}\right.$ : $t \in[0, T]\}$ if the event $\{\tau \leq t\}$ belongs to the $\sigma$-field $\mathcal{F}_{t}$ for every $t \in[0, T]$. That is, $\tau$ is a stopping time if an observer can tell, on the basis of his current information, whether $\tau$ has occurred before or at the current time $t$. Let $\mathcal{S}_{0, T}$ denote the set of stopping times taking values in $[0, T]$.

Consider a contingent claim $(f, Y)$ and an exogenously specified stopping time $\tau \in \mathcal{S}_{0, T}$. Here $f \equiv\left\{f_{t}, \mathcal{F}_{t}: t \in[0, \tau]\right\}$ is a cumulative payment process prior to $\tau$ which is nondecreasing, progressively measurable, right-continuous and null at zero. Also $Y$ is used to represent a terminal, nonnegative and $\mathcal{F}_{\tau}$-measurable cash flow $Y_{\tau}$ at time $\tau$. By analogy with Section 1.2 we consider $(f, Y)$ which satisfy the integrability condition

$$
E\left[\xi_{\tau} Y_{\tau}\right]+E\left[\int_{0}^{\tau} \xi_{s} d f_{s}\right]<\infty,
$$

for all $\tau \in \mathcal{S}_{0, T}$. Let $I S$ denote this class of claims.

Theorem 1.3.1. Let $\tau$ denote a stopping time in $\mathcal{S}_{0, T}$ and suppose that $(f, Y) \in I S$. The rational price of this contingent claim is uniquely given by

$$
E^{*}\left[\int_{t}^{\tau} R_{t, s} d f_{s} \mid \mathcal{F}_{t}\right]+E^{*}\left[R_{t, \tau} Y_{\tau} \mid \mathcal{F}_{t}\right]
$$

at any time $t \in[0, \tau]$.

If, instead of being exogenously specified, the stopping time $\tau$ can be chosen by the holder of the contingent claim, $(f, Y)$ is an American 
contingent claim. Since this choice can only be based on the information available (and since information is assumed to be homogeneous among participants in the financial market) the exercise decision can be thought of as the selection of the best stopping time $\tau$ of the filtration with values in $[0, T]$. The next theorem shows that the value of the contract is the value under the best exercise policy.

Theorem 1.3.2. ([Bensoussan [1984]], [Karatzas [1988]]) Suppose that $(f, Y) \in I S$. Consider an American contingent claim $(f, Y)$. The rational price $V_{t}(f, Y)$ of this claim is uniquely given by

$$
V_{t}(f, Y)=\sup _{\tau \in \mathcal{S}_{t, T}}\left(E^{*}\left[\int_{t}^{\tau} R_{t, s} d f_{s} \mid \mathcal{F}_{t}\right]+E^{*}\left[R_{t, \tau} Y_{\tau} \mid \mathcal{F}_{t}\right]\right),
$$

at time $t \in[0, T]$.

Proof of Theorem 1.3.2. We prove the theorem for the case $f=0$. The proof follows [Karatzas [1988]]. For $t \in[0, T]$ define the discounted payoff process

$$
D_{t} \equiv R_{0, t} Y_{t} .
$$

From the theory of optimal stopping (see, for instance, [El Karoui [1981]]) we conclude that there exists a nonnegative, right-continuous with lefthand limits $Q$-supermartingale $Z \equiv\left\{Z_{t}, \mathcal{F}_{t}: t \in[0, T]\right\}$ such that

$$
Z_{t}=\sup _{\tau \in \mathcal{S}_{t, T}} E^{*}\left[D_{\tau} \mid \mathcal{F}_{t}\right]
$$

for all $t \in[0, T]$. The process $Z$ is the Snell envelope of $D$. Furthermore, the optimal stopping time $\tau_{t}$ is given by

$$
\tau_{t} \equiv \inf \left\{s \in[t, T]: Z_{s}=D_{s}\right\} .
$$

In order to show that (1.3.3) correctly values the American contingent claim we must show that $Z$ is attainable by an admissible consumptionportfolio strategy $(C, \pi)$ whose value is (1.3.3).

The Snell envelope $Z$ is a process of class $D[0, T]$ and is regular ([Karatzas and Shreve [1988, Chapter 1, Definitions 4.8 and 4.12]]). Hence the DoobMeyer decomposition holds,

$$
Z_{t}=Z_{0}+M_{t}-A_{t}, t \in[0, T],
$$

where $M$ is a $Q$-martingale and $A$ is a continuous, nondecreasing process with $M_{0}=A_{0}=0$. The Martingale Representation Theorem also implies that

$$
M_{t}=\int_{0}^{t} \phi_{s} d \tilde{z}_{s}, t \in[0, T]
$$


where $\phi \equiv\left\{\phi_{t}, \mathcal{F}_{t}: t \in[0, T]\right\}$ is a one-dimensional, $\mathcal{F}_{t}$-progressively measurable process. Selecting the portfolio and consumption (withdrawal) processes

$$
\begin{aligned}
\pi_{1 t} & \equiv R_{0, t}^{-1} \sigma_{t}^{-1} \phi_{t} \\
C_{t} & \equiv \int_{0}^{t} R_{0, s}^{-1} d A_{s},
\end{aligned}
$$

defining the process

$$
X_{t} \equiv R_{0, t}^{-1} Z_{t},
$$

and applying Itô's lemma to $X$ yields, for $t \in[0, T]$,

$$
\begin{aligned}
d X_{t} & =r_{t} R_{0, t}^{-1} Z_{t} d t+R_{0, t}^{-1}\left(d M_{t}-d A_{t}\right) \\
& =r_{t} X_{t} d t+R_{0, t}^{-1}\left(\phi_{t} d \tilde{z}_{t}-d A_{t}\right) \\
& =r_{t} X_{t} d t+\pi_{1 t} \sigma_{t} d \tilde{z}_{t}-d C_{t}
\end{aligned}
$$

Hence $X$ is a well-defined wealth process which corresponds to the admissible strategy $(C, \pi)$. That is $(C, \pi)$ is an admissible strategy which attains $Z$ and $X$ is the corresponding wealth process. We conclude that

$$
\begin{aligned}
X_{t} \equiv R_{0, t}^{-1} Z_{t} & =R_{0, t}^{-1} \sup _{\tau \in \mathcal{S}_{t, T}} E^{*}\left[D_{\tau} \mid \mathcal{F}_{t}\right] \\
& =R_{0, t}^{-1} \sup _{\tau \in \mathcal{S}_{t, T}} E^{*}\left[R_{0, \tau} Y_{\tau} \mid \mathcal{F}_{t}\right] \\
& =\sup _{\tau \in \mathcal{S}_{t, T}} E^{*}\left[R_{t, \tau} Y_{\tau} \mid \mathcal{F}_{t}\right]
\end{aligned}
$$

for all $t \in[0, T]$. This establishes the valuation formula (1.3.3) of the theorem.

Remark 1.3.3. Theorem 1.3.2 and its proof also demonstrate that the discounted price of an American contingent claim without a flow of payments (i.e., with $f=0$ ) is a $Q$-martingale prior to the optimal exercise time $\tau_{0}$. It follows that $Z_{t}-Z_{0}=\int_{0}^{t}\left(d M_{t}-d A_{t}\right)$, is a martingale prior to the exercise time $\tau$. We conclude that $\int_{0}^{t} \mathbf{1}_{\left\{s<\tau_{0}\right\}} d A_{s}=0$.

Theorem 1.3.2 states that the price of an American contingent claim is the present value of the payoffs received at or prior to the optimal exercise time. This representation of the price, although intuitive, is often impractical since the optimal stopping time, in most cases, cannot be computed explicitly. An alternative representation which emphasizes the gains from early exercise (prior to the maturity date $T$ ) often provides additional insights into the contributors to the value of such a claim. 
The early exercise premium representation is, in fact, the Riesz decomposition of the Snell envelope. This decomposition was initially demonstrated by [El Karoui and Karatzas [1991]] for a class of stopping time problems. [Myneni [1992]] adapts their results to the valuation of American put options in an economy in which the interest rate is constant and the underlying asset price follows a geometric Brownian motion process. A generalization of the Riesz decomposition to a class of semimartingales adapted to a filtration satisfying the "usual conditions" appears in [Rutkowski [1994]]. The results reported below are special cases of Rutkowski since the underlying uncertainty-information structure, in our economy, is given by the Brownian filtration introduced in Section 1.2.2.

Consider a contingent claim whose payoff $Y$, under the $Q$-measure, satisfies

$$
Y_{t}=Y_{0}+A_{t}(Y)+M_{t}(Y), t \in[0, T]
$$

where $M(Y)$ is a $Q$-martingale and $A(Y)$ is a nondecreasing process null at 0 ; both $M(Y)$ and $A(Y)$ are progressively measurable processes of the Brownian filtration. For the example of a call option the exercise payoff is $Y=(S-K)^{+}$. This payoff can be decomposed in the form (1.3.5) by an application of the Tanaka-Meyer formula ([Karatzas and Shreve [1988, Chapter 3, Proposition 6.8]]).

Theorem 1.3.4. Let $(0, Y) \in I S$. The value of the American contingent claim whose only payoff is the terminal payoff $Y$ at the exercise time has the early exercise premium representation

$V_{t}(Y)=E^{*}\left[R_{0, T} Y_{T} \mid \mathcal{F}_{t}\right]+E^{*}\left[\int_{\tau_{t}}^{T} R_{\tau_{t}, s} \mathbf{1}_{\left\{\tau_{s}=s\right\}}\left(r_{s} Y_{s} d s-d A_{s}(Y)\right) \mid \mathcal{F}_{t}\right], t \in[0, T]$,

where $\tau_{t}=\inf \left\{v \in[t, T]: S_{v}=Z_{v}\right\}$.

Equation (1.3.6) provides an intuitive decomposition of the price of the American contingent claim. It indicates that the price of the contract is the value of a European contingent claim with matching characteristics augmented by the gains from early exercise (the early exercise premium). As we shall see in the next section in a more specific context, the early exercise premium has a nice interpretation in the case of an American option.

Proof of Theorem 1.3.4. The proof follows from Lemma 1.3.5 below and from the fact that the process

$$
Z_{t}+\int_{0}^{t} \mathbf{1}_{\left\{\tau_{v}=v\right\}} R_{0, v}\left[r_{v} Y_{v} d v-d A_{v}(Y)\right], t \in[0, T]
$$

is a $Q$-martingale (see [Rutkowski [1994, Lemmas A.2, A.3, and A.4]]). 
Lemma 1.3.5. Let $Z_{t} \equiv \sup _{\tau \in \mathcal{S}_{t, T}} E^{*}\left[D_{\tau} \mid \mathcal{F}_{t}\right], t \in[0, T]$ and suppose that the process given in (1.3.7) is a $Q$-martingale. Then the representation (1.3.6) holds.

Proof of Lemma 1.3.5. Since the process in (1.3.7) is a $Q$-martingale we can write

$$
E^{*}\left[Z_{T}+\int_{0}^{T} \mathbf{1}_{\left\{\tau_{v}=v\right\}} R_{0, v}\left(r_{v} Y_{v} d v-d A_{v}(Y)\right)\right]=E^{*}\left[Z_{0}\right] .
$$

By definition

$$
Z_{T}=\sup _{\tau \in \mathcal{S}_{T, T}} E^{*}\left[D_{\tau} \mid \mathcal{F}_{T}\right]=E^{*}\left[D_{T} \mid \mathcal{F}_{T}\right]=D_{T} .
$$

and

$$
Z_{0}=\sup _{\tau \in \mathcal{S}_{0, T}} E^{*}\left[D_{\tau} \mid \mathcal{F}_{0}\right]=E^{*}\left[D_{\tau_{0}} \mid \mathcal{F}_{0}\right]
$$

Substituting (1.3.9) and (1.3.10) in (1.3.8) yields

$$
E^{*}\left[D_{T}\right]+E^{*}\left[\int_{0}^{T} \mathbf{1}_{\left\{\tau_{v}=v\right\}} R_{0, v}\left(r_{v} Y_{v} d v-d A_{v}(Y)\right)\right]=E^{*}\left[D_{\tau_{0}}\right] .
$$

By Theorem 1.3.2 the righthand side of (1.3.11) equals $V_{0}(Y)$. Since $\mathbf{1}_{\left\{\tau_{v}=v\right\}}=0$ in the random interval $\left[0, \tau_{0}\right]$ we conclude that the assertion of the lemma holds.

Corollary 1.3.6. Contingent claims such that $r_{v} Y_{v} d v-d A_{v}(Y) \leq 0$ for all $v \in[0, T]$ will never be exercised prior to the maturity date.

Proof of Corollary 1.3.6. Under the condition stated early exercise can only lead to a reduction in the value of the contract. Hence, it is never optimal to exercise prior to maturity.

It is well known that it is suboptimal to exercise an American call option on a nondividend-paying stock prior to maturity ([Merton [1973]]). For this contract $Y=(S-K)^{+}$and, in the exercise region, $r_{v} Y_{v} d v-$ $d A_{v}(Y)=r_{v}\left(S_{v}-K\right) d v-S_{v} r_{v} d v=-r_{v} K d v<0$. Corollary 1.3.6 then applies and shows that early exercise is a suboptimal strategy.

An alternative to the early exercise premium representation of the American contingent claim is a decomposition which emphasizes the gains from delayed exercise. The delayed exercise premium representation for the American put option on a nondividend-paying asset and in a financial market with constant coefficients (constant interest rate and GBMP for the stock price) is due to [Carr, Jarrow and Myneni [1992]]. The next theorem extends their results to the more general class of American contingent claims discussed in this section. 
Theorem 1.3.7. The value of the American contingent claim with payoff $Y$ at the exercise time, such that $(0, Y) \in I S$, has the delayed exercise premium representation

$$
V_{t}(Y)=Y_{t}+E^{*}\left[\int_{t}^{T} R_{t, s} \mathbf{1}_{\left\{\tau_{t}>s\right\}}\left(d A_{s}(Y)-r_{s} Y_{s} d s\right) \mid \mathcal{F}_{t}\right], t \in[0, T],
$$

where $\tau_{t}=\inf \left\{v \in[t, T]: S_{v}=Z_{v}\right\}$.

Proof of Theorem 1.3.7. The value of the contingent claim can always be written as

$$
V_{t}(Y)=Y_{t}+E^{*}\left[\left(R_{t, \tau_{t}} Y_{\tau_{t}}-Y_{t}\right) \mid \mathcal{F}_{t}\right], t \in[0, T] .
$$

An application of Itô's lemma yields

$$
V_{t}(Y)=Y_{t}+E^{*}\left[\int_{t}^{\tau_{t}} R_{t, s}\left(d A_{s}(Y)+d M_{s}(Y)-r_{s} Y_{s} d s\right) \mid \mathcal{F}_{t}\right], t \in[0, T] .
$$

The representation (1.3.12) follows since $M(Y)$ is a $Q$-martingale.

\subsection{Standard American Options: The GBMP Model}

We now focus on standard American option contracts in an economy in which the underlying asset price follows a geometric Brownian motion process (GBMP).

Consider an American call option with exercise price $K>0$ and maturity date $T$, written on an underlying asset whose price $S$ satisfies the stochastic differential equation (under the $Q$-measure)

$$
d S_{t}=S_{t}\left[(r-\delta) d t+\sigma d \tilde{z}_{t}\right], t \in[0, T] ; S_{0} \text { given. }
$$

Here $r, \delta$, and $\sigma$ are constant parameters; $r$ is the interest rate and $\delta$ represents the dividend rate paid on the asset. Since exercise can only be optimal when $S>K$ the option payoff upon exercise is $Y=(S-K)^{+}$.

Our first result characterizes the structure of the exercise region and its boundary. Since the environment is Markovian the state space is completely described by $(S, t)$. Let $\mathcal{E} \equiv\left\{(S, t) \in \mathbf{R}^{+} \times[0, T]: C(S, t)=\right.$ $\left.(S-K)^{+}\right\}$denote the immediate exercise region. Its complement is the continuation region $\mathcal{C} \equiv\left\{(S, t) \in \mathbf{R}^{+} \times[0, T]: C(S, t)>(S-K)^{+}\right\}$.

Proposition 1.4.1. The immediate exercise region has the following properties

(1) right-connectedness: $(S, t) \in \mathcal{E}$ implies $(S, s) \in \mathcal{E}$ for all $t \in[0, T]$ and $s \in[t, T]$.

(2) up-connectedness: $(S, t) \in \mathcal{E}$ implies $(\lambda S, t) \in \mathcal{E}$ for $\lambda \geq 1$, for all $t \in[0, T]$.

(3) Suppose that $S \leq \max \{K,(r / \delta) K\}$. Then $(S, t) \notin \mathcal{E}$, for all $t \in$ $[0, T]$. 
Proof of Proposition 1.4.1. Recall that $\mathcal{S}_{s, T}$ denotes the set of stopping times of the Brownian filtration with values in $[s, T]$.

(1) Since $s \geq t$ we have $\mathcal{S}_{s, T} \subseteq \mathcal{S}_{t, T}$ and therefore $C(S, t) \geq C(S, s)$. By assumption, immediate exercise is optimal at $t$. Thus $(S-$ $K)^{+} \geq C(S, s)$.

(2) Consider $S^{1}>S^{2}$ and suppose that $\left(S^{2}, t\right) \in \mathcal{E}$ while $\left(S^{1}, t\right) \notin \mathcal{E}$. Let $\tau_{1}$ denote the optimal stopping time at $\left(S^{1}, t\right)$. For $s \geq t$ define the exponential process $N_{t, s} \equiv \exp \left[\left(r-\delta-\frac{1}{2} \sigma^{2}\right)(s-t)+\sigma\left(\tilde{z}_{s}-\tilde{z}_{t}\right)\right]$ and note that $S_{s}=S_{t} N_{t, s}$. We have the following sequence of relations

$$
\begin{aligned}
C\left(S^{1}, t\right)= & E^{*}\left[e^{-r\left(\tau_{1}-t\right)}\left(S^{1} N_{t, \tau_{1}}-K\right)^{+}\right] \quad\left(\text { optimality of } \tau_{1} \text { at }\left(S^{1}, t\right)\right) \\
= & E^{*}\left[e^{-r\left(\tau_{1}-t\right)}\left(S^{2} N_{t, \tau_{1}}+\left(S^{1}-S^{2}\right) N_{t, \tau_{1}}-K\right)^{+}\right] \\
\leq & E^{*}\left[e^{-r\left(\tau_{1}-t\right)}\left(S^{2} N_{t, \tau_{1}}-K\right)^{+}\right]+E^{*}\left[e^{-r\left(\tau_{1}-t\right)}\left(S^{1}-S^{2}\right) N_{t, \tau_{1}}\right] \\
& \quad\left(\text { since }(a+b)^{+} \leq a^{+}+b^{+}\right) \\
\leq & C\left(S^{2}, t\right)+\left(S^{1}-S^{2}\right) E^{*}\left[e^{-r\left(\tau_{1}-t\right)} N_{t, \tau_{1}}\right] \\
& \quad\left(\text { suboptimality of } \tau_{1} \text { at }\left(S^{2}, t\right)\right) \\
\leq & C\left(S^{2}, t\right)+S^{1}-S^{2} \\
& \quad\left(S^{1}-S^{2}>0 \text { and supermartingale property of } S\right) \\
\leq & \left(S^{2}-K\right)+S^{1}-S^{2}=S^{1}-K
\end{aligned}
$$

(optimality of immediate exercise at $\left(S^{2}, t\right)$ )

Hence $C\left(S^{1}, t\right) \leq S^{1}-K$, which contradicts the assumed suboptimality of immediate exercise at $\left(S^{1}, t\right)$.

(3) Suppose that $0<S \leq K$. Since $P\left[S_{v}>K\right]>0$ for some $v \in$ $[t, T]$ immediate exercise is a suboptimal policy. Suppose that $K<S \leq(r / \delta) K$ and assume that immediate exercise is optimal, i.e., $C(S, t)=S-K$. Consider the portfolio consisting of 1 call option, 1 share of the stock held short and $K$ dollars invested at the riskfree rate. Define the stopping time $\tau \equiv \tau_{(r / \delta) K}=$ $\inf \left\{v \in[t, T]: S_{v}=(r / \delta) K\right\}$ or $\tau_{(r / \delta) K}=T$ if no such time exists. Suppose that we liquidate this portfolio at the stopping time $\tau$. The cash flows generated by this investment strategy are

Time $t \quad$ Time $\tau$

\begin{tabular}{rcc} 
Buy call & $-C(S, t)=-(S-K)$ & $\left(S_{\tau}-K\right)^{+}$ \\
Sell stock & $+S$ & $-S_{\tau}-\int_{t}^{\tau} e^{r(\tau-v)} \delta S_{v} d v$ \\
Invest $K$ & $-K$ & $K+\int_{t}^{\tau} e^{r(\tau-v)} r K d v$ \\
\hline Total & 0 & $\left(K-S_{\tau}\right)^{+}+\int_{t}^{\tau} e^{r(\tau-v)}\left(r K-\delta S_{v}\right) d v$
\end{tabular}




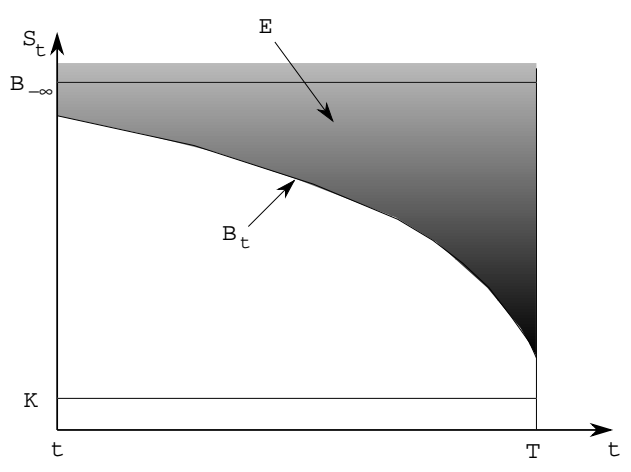

Figure 1.4.2. Exercise Region for a Standard American Option

Since $\left(r K-\delta S_{v}\right)>0$ for all $v<\tau$ this strategy is an arbitrage strategy. Since the existence of an equilibrium implies the absence of arbitrage opportunities it must be the case that $C(S, t)>(S-$ $K)$, i.e., immediate exercise is a suboptimal strategy.

An illustration of the exercise region and corresponding boundary for a standard American option is given in Figure 1.4.2. The next proposition states some basic properties of the price function. Properties of the call and put price functions in more general market models are explored in detail in [Grundy and Wiener [1995]].

Proposition 1.4.3. Let $C(S, t)$ denote the value of the American call option. We have

(1) $C(S, t)$ is continuous on $\mathbf{R}^{+} \times[0, T]$.

(2) $C(\cdot, t)$ is nondecreasing and convex on $\mathbf{R}^{+}$for all $t \in[0, T]$.

(3) $C(S, \cdot)$ is nonincreasing on $[0, T]$ for all $S \in \mathbf{R}^{+}$.

(4) $0 \leq \partial C(S, t) / \partial S \leq 1$ on $\mathbf{R}^{+} \times[0, T] ; \partial C(S, t) / \partial S=1$ for $(S, t)$ in the interior of $\mathcal{E}$.

(5) $\partial C(S, t) / \partial S$ is continuous on $\mathbf{R}^{+}$for all $t \in[0, T)$.

Proof of Proposition 1.4.3.

(1) This follows from the continuity of the option payoff function and the continuity of the flow of the stochastic differential equation (1.4.1) relative to the initial values.

(2) This follows from the monotonocity (increasing) of the flow and the increasing and convex structure of the payoff.

(3) This is a straightforward counterpart of Proposition 1.4.1 (1).

(4) Consider $\left(S^{1}, t\right)$ and $\left(S^{2}, t\right)$ such that $S^{1}>S^{2}$. For any stopping 
time $\tau \in \mathcal{S}_{0, T}$ we have

$0 \leq\left[\left(S_{\tau}^{1}-K\right)^{+}-\left(S_{\tau}^{2}-K\right)^{+}\right] \leq\left(S_{\tau}^{1}-S_{\tau}^{2}\right)=\left(S^{1}-S^{2}\right) N_{t, \tau}$.

In particular this holds for the optimal stopping time $\tau_{1}$ associated with $\left(S^{1}, t\right)$. Hence, we can write

$$
\begin{aligned}
0 \leq & C\left(S^{1}, t\right)-C\left(S^{2}, t\right) \\
= & E^{*}\left[e^{-r\left(\tau_{1}-t\right)}\left(S^{1} N_{t, \tau_{1}}-K\right)^{+} \mid \mathcal{F}_{t}\right] \\
& \quad-E^{*}\left[e^{-r\left(\tau_{2}-t\right)}\left(S^{2} N_{t, \tau_{2}}-K\right)^{+} \mid \mathcal{F}_{t}\right] \\
\leq & E^{*}\left[e^{-r\left(\tau_{1}-t\right)}\left(S^{1}-S^{2}\right) N_{t, \tau_{1}} \mid \mathcal{F}_{t}\right] \\
& \quad\left(\text { suboptimality of } \tau_{1} \text { at }\left(S^{2}, t\right)\right) \\
= & \left(S^{1}-S^{2}\right) E^{*}\left[e^{-r\left(\tau_{1}-t\right)} N_{t, \tau_{1}} \mid \mathcal{F}_{t}\right] \\
\leq & \left(S^{1}-S^{2}\right)
\end{aligned}
$$

where the last inequality follows since $S^{1}-S^{2}>0$ and since the discounted price of a dividend-paying asset is a $Q$-supermartingale. Dividing both sides by $S^{1}-S^{2}$ proves the statement (this argument also establishes the continuity of the option price with respect to $S$ ).

Property (1) implies that the immediate exercise region is a closed set (the continuation region is an open set). We conclude that the boundary of the immediate exercise region is well defined as $B \equiv\left\{B_{t}: t \in[0, T]\right\}$ where $B_{t} \equiv \inf \{S:(S, t) \in \mathcal{E}\}$ and belongs to $\mathcal{E}$. The boundary has the following structure.

Proposition 1.4.4. The boundary of the immediate exercise region is continuous, nonincreasing and has limiting values $\lim _{t \uparrow T} B_{t}=\max \{K,(r / \delta) K\}$ and $\lim _{T-t \uparrow \infty} B_{t}=B_{-\infty} \equiv K(b+f) /\left(b+f-\sigma^{2}\right)$ where $b \equiv \delta-r+\frac{1}{2} \sigma^{2}$ and $f \equiv\left(b^{2}+2 r \sigma^{2}\right)^{\frac{1}{2}}$.

The continuity and monotonocity of the boundary $B$ follow from Proposition 1.4.1 properties (1) and (2). The limiting values are obtained from the recursive equation (1.4.5) for the exercise boundary in Theorem 1.4.5 below. Note that the optimal exercise boundary for the deterministic problem with $\sigma=0$ is $\max \{K,(r / \delta) K\}$. For the stochastic problem the remaining uncertainty faced by the investor $\sigma(T-t)$ converges to zero as $t \uparrow T$ and we expect the optimal exercise boundary to converge to the boundary for the deterministic problem. This is the intuition underlying this limiting result stated in Proposition 1.4.4. The American option exercise boundary is studied in detail in [Ait-Sahlia [1995]] and [Barles, et al. [1995]]. See also [van Moerbeke [1976]].

In the GMBP case Theorem 1.3.4 specializes as follows. 
Theorem 1.4.5. ([Kim [1990]], [Jacka [1991]], [Carr, Jarrow and Myneni [1992]]) Suppose that the underlying asset price follows the geometric Brownian motion process (1.4.1) and that the interest rate is constant. The value of an American call option has the early exercise premium representation

$(1.4 .2)$

$C\left(S_{t}, t\right)=C^{e}\left(S_{t}, t\right)$

$$
+\int_{t}^{T}\left(\delta S_{t} e^{-\delta(s-t)} N\left(d_{2}\left(S_{t}, B_{s}, s-t\right)\right)-r K e^{-r(s-t)} N\left(d_{3}\left(S_{t}, B_{s}, s-t\right)\right)\right) d s,
$$

for $t \in[0, T]$, where $C^{e}(S, t)$ represents the Black-Scholes value of a European call option (equation (1.2.19)) and

$$
\begin{gathered}
d_{2}\left(S_{t}, B_{s}, s-t\right)=\left(\log \left(S_{t} / B_{s}\right)+\left(r-\delta+\frac{1}{2} \sigma^{2}\right)(s-t)\right) /(\sigma \sqrt{s-t}) \\
d_{3}\left(S_{t}, B_{s}, s-t\right)=d_{2}\left(S_{t}, B_{s}, s-t\right)-\sigma \sqrt{s-t}
\end{gathered}
$$

The immediate exercise boundary B solves the backward nonlinear integral equation

(1.4.5)

$B_{t}-K=C^{e}\left(B_{t}, t\right)$

$$
+\int_{t}^{T}\left(\delta B_{t} e^{-\delta(s-t)} N\left(d_{2}\left(B_{t}, B_{s}, s-t\right)\right)-r K e^{-r(s-t)} N\left(d_{3}\left(B_{t}, B_{s}, s-t\right)\right)\right) d s,
$$

subject to the boundary condition $B_{T}=\max \{K,(r / \delta) K\}$.

Proof of Theorem 1.4.5. Proposition 1.4.1 implies $B \geq \max \{K,(r / \delta) K\}$. Hence $Y=(S-K)^{+}$equals $S-K$ in the exercise region. If follows that $d Y_{t}=S_{t}\left[(r-\delta) d t+\sigma d \tilde{z}_{t}\right]$ in the exercise region, i.e., $d A_{t}(Y)=S_{t}(r-\delta) d t$ on $\left\{S_{t} \geq B_{t}\right\}$. Theorem 1.3.4 then implies

$$
\begin{aligned}
C\left(S_{t}, t\right) & =C^{e}\left(S_{t}, t\right)+E^{*}\left[\int_{t}^{T} e^{-r(v-t)}\left[r\left(S_{v}-K\right)-(r-\delta) S_{v}\right] \mathbf{1}_{\left\{S_{v} \geq B_{v}\right\}} d v \mid \mathcal{F}_{t}\right] \\
& =C^{e}\left(S_{t}, t\right)+E^{*}\left[\int_{t}^{T} e^{-r(v-t)}\left[\delta S_{v}-r K\right] \mathbf{1}_{\left\{S_{v} \geq B_{v}\right\}} d v \mid \mathcal{F}_{t}\right]
\end{aligned}
$$

Under the GBMP assumption the expectation in (1.4.6) can be computed explicitly. This leads to (1.4.2). The recursive equation for the optimal exercise boundary follows from the boundary condition $C(B, t)=B-K$.

When the option maturity becomes infinite the option price expression (1.4.2) simplifies as follows ([Samuelson [1965]] and [Merton [1973]]). 
Corollary 1.4.6. (American options with infinite maturity) Consider an American call option with infinite maturity. Its value is $C(S, t)=$ $\left(B_{\infty}-K\right)\left(S / B_{\infty}\right)^{2 \alpha / \sigma^{2}}$, where $B_{\infty}=K(b+f) /\left(b+f-\sigma^{2}\right), \alpha=\frac{1}{2}(b+f)$, $b=\delta-r+\frac{1}{2} \sigma^{2}$, and $f=\sqrt{b^{2}+2 r \sigma^{2}}$.

Proof of Corollary 1.4.6. When $T \uparrow \infty$ the immediate exercise boundary becomes time independent: $B=B_{\infty}$. Then $d_{2}\left(B_{\infty}, B_{\infty}, s-t\right)=(r-$ $\left.\delta+\frac{1}{2} \sigma^{2}\right)(s-t) /(\sigma \sqrt{s-t})$ and $d_{3}\left(B_{\infty}, B_{\infty}, s-t\right)=d_{2}\left(B_{\infty}, B_{\infty}, s-t\right)-$ $\sigma \sqrt{s-t}$ are independent of $B_{\infty}$. Since the European call option value also converges to 0 the recursive equation (1.4.5) becomes linear in $B_{\infty}$ and has solution $B_{\infty}=K(b+f) /\left(b+f-\sigma^{2}\right)$. The value of the option then follows from (1.4.2): the early exercise premium simplifies to $\left(B_{\infty}-\right.$ $K)\left(S / B_{\infty}\right)^{2 \alpha / \sigma^{2}}$.

The next proposition gives a relationship between American puts and calls which enables us to infer the value of a put on a dividend-paying asset by a simple reparametrization of the American call pricing function. This symmetry result is a variation of the international put-call equivalence ([Grabbe [1983]]) and was originally proved in [McDonald and Schroder [1990]].

Proposition 1.4.7. (American put-call symmetry) Consider American put and call options written on the same underlying asset whose price satisfies (1.4.1). Suppose that these options have the same maturity and the same exercise price. Let $P(S, K, r, \delta, T)$ and $C(S, K, r, \delta, T)$ denote the respective price functions. Then

$$
P(S, K, r, \delta, T)=C(K, S, \delta, r, T) .
$$

Corollary 1.4.7 implies that a put with exercise price $K$ and maturity $T$, written on a stock with dividend rate $\delta$ and price $S$ in a market with interest rate $r$ has the same value as a call with exercise price $S$ and maturity $T$ written on a stock with dividend rate $r$ and price $K$ when the interest rate is $\delta$.

The model for the underlying asset price in (1.4.1) allows for dividends which are paid at a continuous rate. This type of model has been used to value foreign currency options, futures options, and index options. See, e.g., [Hull [1993]] for a description of these contracts. Analytical solutions for American options in the case of discrete dividends are given in [Roll [1977]], [Geske [1979]], and [Whaley [1981]]. Numerical techniques for the valuation of American options were initiated in [Schwartz [1977]] and Brennan and Schwartz [[1977], [1978]]. Convergence of the Brennan and Schwartz method is proved in [Jaillet, Lamberton, and Lapeyre 
[1990]]. Probably the most widely used numerical technique is the binomial method developed in [Cox, Ross, and Rubinstein [1979]] and [Cox and Rubinstein [1985]]. Convergence of the binomial method for pricing American options is proved in [Amin and Khanna [1994]]. A new numerical technique and a comparison of existing methods is given in [Broadie and Detemple [1994a]].

Pricing results for American bond and yield options are given in [Chesney, Elliot, and Gibson [1993]]. Results for American options on multiple assets are derived in [Broadie and Detemple [1994b]]. The pricing of American capped options is considered in the next section.

\subsection{American Capped Options}

In the past few years several contracts with cap provisions have been issued by financial institutions. One example is the MILES contract (Mexican Index-Linked Euro Security). This contract is an American call option on the dollar value of the Mexican stock index. The contract is somewhat unusual since it has both a cap and a restriction on the exercise period.

Other examples of capped options are the capped options on the S\&P 100 and S\&P 500 indices that were introduced by the Chicago Board of Options Exchange (CBOE) in November 1991. These capped index options combine a European exercise feature (the holder of the security cannot exercise until the maturity of the contract) with an automatic exercise provision. The automatic exercise provision is triggered if the index value exceeds the cap at the close of the day. See [Flesaker [1992]] for a critical analysis of these options. Additional examples of European capped options include the range forward contract, collar loans, barrier options, indexed notes and index currency option notes (see [Boyle and Turnbull [1989]] and [Rubinstein and Reiner [1991]]).

Our treatment in this section follows [Broadie and Detemple [1995]]. We first consider options with constant caps (subsection 1.5.1), then extend the analysis to caps that grow at a constant rate (subsection 1.5.2), and conclude with capped options on nondividend-paying assets with stochastic volatility (subsection 1.5.3). In subsections 1.5.1 and 1.5.2, we suppose that the economy under consideration is the economy of Section 1.4 in which the interest rate is constant and the underlying asset price follows the geometric Brownian motion process (1.4.1).

\subsubsection{Capped Options with a Constant Cap.}

We consider an American capped call option with maturity date $T$, exercise price $K$ and constant cap $L$ with $L>K$. Upon exercise this contract pays $(S \wedge L-K)^{+}$. Let $B^{L}$ and $C^{L}(S, t)$ denote the optimal exercise boundary and the price of the capped option, respectively. The optimal 


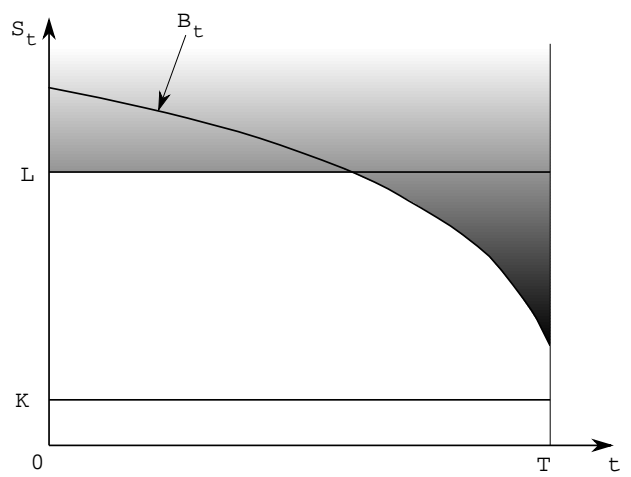

Figure 1.5.2. Exercise Region for an American Capped Call Option

exercise boundary is characterized in Theorem 1.5.1 and illustrated in Figure 1.5.2.

Theorem 1.5.1. Consider an American capped call option with maturity date $T$, exercise price $K$ and constant cap equal to $L$ with $L>K$. The optimal exercise boundary $B^{L}$ is given by

$$
B^{L}=L \wedge B,
$$

where $B$ denotes the optimal exercise boundary of an American uncapped call option with same maturity date and exercise price.

Proof of Theorem 1.5.1. Case (i): Suppose first that $S \geq L$. Then immediate exercise is optimal since the exercise payoff is $(S \wedge L-K)^{+}=L-K$, which is the maximum payoff attainable.

Case (ii): Suppose that $B \leq S<L$. Since $(S \wedge L-K)^{+} \leq(S-K)^{+}$the inequality

$$
C^{L}(S, t) \leq C(S, t)
$$

always holds. In the region under consideration immediate exercise is optimal for the holder of the uncapped option. Thus $C^{L}(S, t) \leq(S-$ $K)^{+}=(S-K)$. Since immediate exercise is a feasible strategy for the holder of the uncapped option with a payoff equal to $(S \wedge L-K)^{+}=$ $(S-K)^{+}=(S-K)$, we conclude that immediate exercise is optimal for the uncapped option as well (if not there exists a waiting strategy which dominates immediate exercise for the capped option, hence for the uncapped option - a contradiction since we are in the case $S \geq B$ ). 
Case (iii): Suppose that $S<B \wedge L$. We must show that immediate exercise is suboptimal. Consider first the case $L>\max \{(r / \delta) K, K\}$. Let $B(T, t)$ denote the exercise boundary for an uncapped option with exercise price $K$ and maturity date $T$. Recall that $B(T, t)$ is a strictly decreasing function of time and converges to $K \wedge(r / \delta) K$ as $t$ converges to $T$. Hence, in the case under consideration, we can always find a shorter maturity $T_{0}, T_{0} \leq T$, such that $S_{t}<B\left(T_{0}, t\right)<L$. Clearly the strategy of exercising at the first hitting time of the set $\left[B\left(T_{0}, t\right), \infty\right)$ is feasible for the holder of the capped option. This strategy also has the same payoff as the uncapped option with shorter maturity $T_{0}$. We conclude that

$$
C\left(S, t, T_{0}\right) \leq C^{L}(S, t) .
$$

Since immediate exercise is suboptimal for the shorter maturity uncapped option when $S<B\left(T_{0}, t\right)$ we must have $(S-K)^{+}<C^{L}(S, t)$. That is, immediate exercise is suboptimal for the capped option. Consider next the case $L \leq(r / \delta) K$. Let $\tau$ denote the minimum of $T$ and of the first hitting time of the set $[L, \infty)$. The policy of exercising at $\tau$ dominates immediate exercise since $\delta S_{v}-r K<0$ for $v \in[t, \tau)$.

Since the early exercise strategy is fully identified, the valuation of the contract is easy to perform. Let $t^{*}$ denote the solution to the equation

$$
B(T, t)=L,
$$

if an interior solution in $[0, T]$ exists. If $B(T, t)<L$ for all $t \in[0, T]$ set $t^{*}=0$. If $B(T, t)>L$ for all $t \in[0, T]$ set $t^{*}=T$.

The next theorem provides a valuation formula for the American capped call option.

Theorem 1.5.3. Consider an American capped call option with maturity date $T$, exercise price $K$ and constant cap equal to $L(L>K)$. For $S \geq L \wedge B$ the option value is $(S \wedge L)-K$. For $S<L \wedge B$ and $t \geq t^{*}$ the option value is $C^{L}(S, t)=C(S, t)$. For $S<L \wedge B$ and $t<t^{*}$ the option is worth $C^{L}(S, t)$ given by

$$
(L-K) E^{*}\left[e^{-r\left(\tau_{L}-t\right)} \mathbf{1}_{\left\{\tau_{L}<t^{*}\right\}} \mid \mathcal{F}_{t}\right]+E^{*}\left[e^{-r\left(t^{*}-t\right)} C\left(S_{t^{*}}, t^{*}\right) \mathbf{1}_{\left\{\tau_{L} \geq t^{*}\right\}} \mid \mathcal{F}_{t}\right],
$$

where $\tau_{L} \equiv \inf \left\{v \in[t, T]: S_{v}=L\right\}$ denotes the first hitting time of $L$ in $[t, T]$ and $\tau_{L} \equiv T$ if no such time exists in $[t, T]$. The representation formula in (1.5.5) can be simplified by computing the expectations explicitly

$$
\begin{gathered}
C^{L}(S, t)=(L-K)\left(\lambda^{2 \phi / \sigma^{2}} N\left(d_{0}\right)+\lambda^{2 \alpha / \sigma^{2}} N\left(d_{0}+2 f \sqrt{t^{*}-t} / \sigma^{2}\right)\right) \\
+e^{-r\left(t^{*}-t\right)} \int_{0}^{L} C\left(x, t^{*}\right) u\left(x, t, t^{*}\right) d x
\end{gathered}
$$


where

$$
\begin{gathered}
u\left(x, t, t^{*}\right)=\left(n\left(d_{1}^{-}(x)\right)-\lambda^{1-2(r-\delta) / \sigma^{2}} n\left(d_{1}^{+}(x)\right)\right) /\left(x \sigma \sqrt{t^{*}-t}\right) \\
d_{0}=\left(\log (\lambda)-f\left(t^{*}-t\right)\right) /\left(\sigma \sqrt{t^{*}-t}\right)
\end{gathered}
$$

and $b=\delta-r+\frac{1}{2} \sigma^{2}, f=\sqrt{b^{2}+2 r \sigma^{2}}, \phi=\frac{1}{2}(b-f), \alpha=\frac{1}{2}(b+f)$, and $\lambda=S / L$.

An alternative decomposition which draws on Theorems 1.3.4 and 1.4.5 relates the value of the American capped option to the value of a capped option with automatic exercise at the cap.

Theorem 1.5.4. (Early exercise premium representation) $\operatorname{Let} C^{a e}(S, t, L)$ denote the value of a capped option with automatic exercise at the cap (see formula (1.5.11) below). For $S<L \wedge B$ and $t \in[0, T]$, the value of the American capped option is given by

$$
C^{L}(S, t)=C^{a e}(S, t, L)+E^{*}\left[\int_{t}^{\tau_{L}} e^{-r(v-t)}\left(\delta S_{v}-r K\right) \mathbf{1}_{\left\{L \geq S_{v} \geq B_{v}\right\}} d v \mid \mathcal{F}_{t}\right],
$$

where $\tau_{L} \equiv \inf \left\{v \in[t, T]: S_{v}=L\right\}$ denotes the first hitting time of $L$ in $[t, T]$, and $\tau_{L} \equiv T$ if no such time exists in $[t, T]$.

This decomposition of the American option value is similar to the early exercise premium representation for standard American options (Theorem 1.4.5). It differs in that it relates the value of the option contract to the value of a contract which may be automatically exercised before the maturity date (the standard representation uses the value of a European option with exercise at the maturity date as the benchmark).

The next result shows that the valuation formulas (1.5.6) and (1.5.10) simplify in the case of sufficiently low dividends.

Corollary 1.5.5. (American capped call valuation with low dividends) Suppose that $\delta \leq r K / L$. For $S<L$ and $t \in[0, T]$, the value of the American capped call option equals the value of the corresponding capped call option with automatic exercise at the cap

$$
\begin{aligned}
& C^{L}(S, t)=C^{a e}(S, t, L) \\
& =(L-K)\left(\lambda^{2 \phi / \sigma^{2}} N\left(d_{0}\right)+\lambda^{2 \alpha / \sigma^{2}} N\left(d_{0}+2 f \sqrt{\tau} / \sigma\right)\right) \\
& \quad+S e^{-\delta \tau}\left(N\left(d_{1}^{-}(L)-\sigma \sqrt{\tau}\right)-N\left(d_{1}^{-}(K)-\sigma \sqrt{\tau}\right)\right) \\
& \quad-\lambda^{-2(r-\delta) / \sigma^{2}} L e^{-\delta \tau}\left(N\left(d_{1}^{+}(L)-\sigma \sqrt{\tau}\right)-N\left(d_{1}^{+}(K)-\sigma \sqrt{\tau}\right)\right) \\
& -K e^{-r \tau}\left(N\left(d_{1}^{-}(L)\right)-N\left(d_{1}^{-}(K)\right)-\lambda^{1-2(r-\delta) / \sigma^{2}}\left(N\left(d_{1}^{+}(L)\right)-N\left(d_{1}^{+}(K)\right)\right)\right) .
\end{aligned}
$$


In (1.5.11) the expressions for $d_{0}$ and $d_{1}^{ \pm}(x)$ are the same as in (1.5.8)(1.5.9) but with $\tau=T-t$ replacing $t^{*}-t$. The expressions for $b, f, \phi$, and $\alpha$ are the same as in Theorem 1.5.4.

Remark 1.5.6. The value of a European capped call option with strike price $K$, cap $L$, and maturity $T$ (the option with payoff $\left(S_{T} \wedge L-K\right)^{+}$ at date $T$ ) is given by

$$
\begin{aligned}
C^{e}(S, t, L)= & S e^{-\delta(T-t)}\left(N\left(d_{1}^{-}(L)-\sigma \sqrt{T-t}\right)-N\left(d_{1}^{-}(K)-\sigma \sqrt{T-t}\right)\right) \\
& -K e^{-r(T-t)}\left(1-N\left(d_{1}^{-}(K)\right)\right)+L e^{-r(T-t)}\left(1-N\left(d_{1}^{-}(L)\right)\right) .
\end{aligned}
$$

The European capped option value can serve as a benchmark to measure the gains from early exercise (prior to maturity) embedded in the American capped option value. The early exercise premium is particularly simple to compute in the case of low dividends (formula (1.5.11)).

Remark 1.5.7. If $L \uparrow \infty$ the European capped call option value $C^{e}(S, t, L)$ converges to the Black-Scholes formula adjusted for dividends (equation $(1.2 .20))$.

\subsubsection{Capped Options with Growing Caps}

We now consider the class of American capped options whose caps grow at a constant rate. Suppose that

$$
L_{t}=L_{0} e^{g t}, t \in[0, T],
$$

where we assume that $L_{0}>K$. Let $t^{*}$ denote the solution to the equation

$$
B(T, t)=L_{t},
$$

if an interior solution in $[0, T]$ exists. If $B(T, t)<L_{t}$ for all $t \in[0, T]$ set $t^{*}=0$. If $B(T, t)>L_{t}$ for all $t \in[0, T]$ set $t^{*}=T$.

In order to determine the optimal exercise region we need to consider the class of exercise strategies defined next and illustrated in Figure 1.5.10.

Definition 1.5.8. $\left(\left(t_{e}, t^{*}, t_{f}\right)\right.$ Exercise Policy) Let $t_{e}$ and $t_{f}$ satisfy $0 \leq$ $t_{e} \leq t_{f} \leq T$ and $t_{e} \leq t^{*} \leq T$. Define the stopping time $\tau_{1}$ by $\inf \{v \in$ $\left.\left[t_{e}, t_{f}\right]: S_{v}=L_{v}\right\}$ or if no such $v$ exists set $\tau_{1}=T$. Set the stopping time $\tau_{2}$ equal to $t_{f}$ if $S_{t_{f}} \geq L_{t_{f}}$ otherwise set $\tau_{2}=T$. Define the stopping time $\tau_{3}$ by $\inf \left\{v \in\left[t^{*}, T\right]: S_{v}=B_{v}\right\}$ or if no such $v$ exists set $\tau_{3}=T$. An exercise policy is a $\left(t_{e}, t^{*}, t_{f}\right)$-policy if the option is exercised at the stopping time $\tau_{1} \wedge \tau_{2} \wedge \tau_{3}$. 


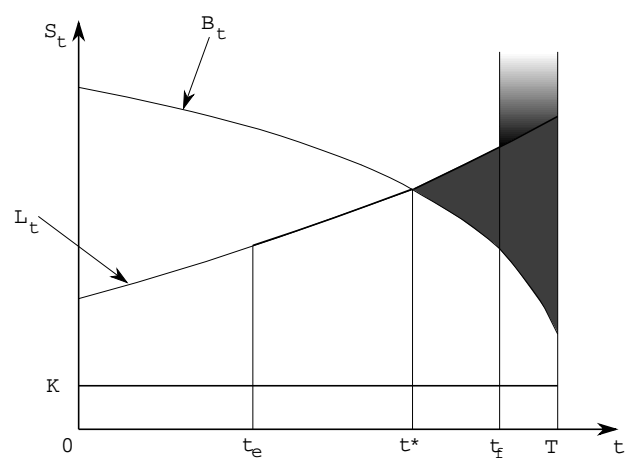

Figure 1.5.10. Exercise Region for a $\left(t_{e}, t^{*}, t_{f}\right)$ Policy

Theorem 1.5.9. Consider an American capped call option with exercise price $K$, maturity date $T$ and cap given by equation (1.5.14). Then the optimal exercise strategy is a $\left(t_{e}, t^{*}, t_{f}\right)$-policy.

Proof of Theorem 1.5.9. Case (i): Suppose first that $B \leq S<L$. Then the same argument as in the proof of Theorem 1.5.1, case (ii) applies and demonstrates that immediate exercise is an optimal strategy.

Case (ii): Consider now the case $S<B \wedge L$ and suppose that $(r / \delta) K>K$. If $L_{t} \geq(r / \delta) K$ the argument in the proof of Theorem 1.5.1, case (iii) applies. If $L_{t}<(r / \delta) K$ the policy of exercising at the stopping time $\tau$ equal to the first hitting time of the set $[(r / \delta) K \wedge L, \infty)$ or $T$ if no such time exists, dominates immediate exercise since $\delta S_{v}-r K<0$ for $v \in[t, \tau)$. In the case $(r / \delta) K \leq K$ we have $L_{t}>K$ for all $t \in[0, T]$ and the argument of Theorem 1.5.1, case (iii), applies again.

Case (iii): Suppose now that $S>L$. It can be verified that the discounted payoff function $e^{-r t}\left(L_{t}-K\right)$ is unimodal with a maximum at

$$
t_{f}=\operatorname{argmax}_{t \in[0, T]} e^{-r t}\left(L_{t}-K\right)
$$

and is strictly increasing for $t<t_{f}$ and strictly decreasing for $t \geq t_{f}$. Hence if $t \geq t_{f}$ immediate exercise strictly dominates any waiting strategy. If $t<t_{f}$ the strategy of exercising at the first hitting time of $L$ or at $t_{f}$ strictly dominates immediate exercise.

Case (iv): Finally, suppose that immediate exercise is optimal at some time $t<t^{*}$ when $S=L$. Then it is optimal to exercise at all $v \in\left[t, t^{*}\right]$ when $S_{v}=L_{v}$. Suppose not, i.e., suppose that there exists $u$ such that 
$S_{u}=L_{u}$ and $C^{L}\left(S_{u}, u\right)>\left(L_{u}-K\right)$. At $t$ we have

$$
\begin{aligned}
L_{t}-K & =C^{L}\left(S_{t}, t\right) \\
& \geq C^{L}\left(S_{t}, t, T-(u-t)\right) \quad(\text { shorter maturity option) } \\
& =C^{H}\left(S_{t}, u, T\right) \quad(H \text { is } L \text { translated by } u-t) \\
& \geq C^{L}\left(S_{u}, u\right)-\left(L_{u}-L_{t}\right) . \quad(\text { see Lemma } 1.5 .11 \text { below) }
\end{aligned}
$$

If immediate exercise is suboptimal at $u$ then $C^{L}\left(S_{u}, u\right)>L_{u}-K$ so that $\left(L_{t}-K\right)>\left(L_{u}-K\right)-\left(L_{u}-L_{t}\right)=L_{t}-K$, a contradiction.

Lemma 1.5.11. Suppose that the underlying asset price $S$ satisfies (1.4.1). Consider two American capped call options written on $S$, with common maturity date $T$ and exercise price $K$, and respective caps $L$ and $H$ satisfying (1.5.14), $L_{0}>H_{0}$. Let $S_{0}^{1}=L_{0}$ and $S_{0}^{2}=H_{0}$. Then $C^{L}\left(S_{0}^{1}, 0\right) \leq$ $C^{H}\left(S_{0}^{2}, 0\right)+L_{0}-H_{0}$.

Proof of Lemma 1.5.11. For any stopping time $\tau \in \mathcal{S}_{0, T}$ we have $0 \leq$ $\left(\left(S_{\tau}^{1} \wedge L_{\tau}-K\right)^{+}-\left(S_{\tau}^{2} \wedge H_{\tau}-K\right)^{+}\right] \leq\left(S_{\tau}^{1} \wedge L_{\tau}-S_{\tau}^{2} \wedge H_{\tau}\right)=S_{0}^{1} N_{0, \tau} \wedge$ $L_{0} e^{g \tau}-S_{0}^{2} N_{0, \tau} \wedge H_{0} e^{g \tau}$. Since $S_{0}^{1}=L_{0}$ and $S_{0}^{2}=H_{0}$ the righthand side of the inequality equals $\left(S_{0}^{1}-S_{0}^{2}\right)\left(N_{0, \tau} \wedge e^{g \tau}\right)$, which is bounded above by $\left(S_{0}^{1}-S_{0}^{2}\right) N_{0, \tau}$. This upper bound on the payoff holds, in particular, for the optimal stopping time $\tau_{1}$ associated with $\left(S_{0}^{1}, 0\right)$. Hence, we can write

$$
\begin{aligned}
0 \leq & C^{L}\left(S_{0}^{1}, 0\right)-C^{H}\left(S_{0}^{2}, 0\right) \\
= & E^{*}\left[e^{-r \tau_{1}}\left(S_{0}^{1} N_{0, \tau_{1}} \wedge L_{0} e^{g \tau_{1}}-K\right)^{+} \mid \mathcal{F}_{0}\right] \\
& \quad-E^{*}\left[e^{-r\left(\tau_{2}-t\right)}\left(S_{0}^{2} N_{0, \tau_{2}} \wedge H_{0} e^{g \tau_{2}}-K\right)^{+} \mid \mathcal{F}_{0}\right] \\
\leq & E^{*}\left[e^{-r \tau_{1}}\left(S_{0}^{1}-S_{0}^{2}\right) N_{0, \tau_{1}} \mid \mathcal{F}_{0}\right] \quad\left(\text { suboptimality of } \tau_{1} \text { at }\left(S_{0}^{2}, 0\right)\right) \\
\leq & S_{0}^{1}-S_{0}^{2} . \quad\left(Q \text {-supermartingale property of } R_{0, t} S_{t}\right)
\end{aligned}
$$

By assumption $S_{0}^{1}=L_{0}$ and $S_{0}^{2}=H_{0}$. So Lemma 1.5.11 follows.

Theorem 1.5.9 shows that the optimal stopping time is a $\left(t_{e}, t^{*}, t_{f}\right)$ exercise policy. The parameters $t^{*}$ and $t_{f}$ are completely determined from the structure of the capped option payoff, the cap process, the underlying asset process, and the interest rate. So $t_{e} \in\left[0, t^{*}\right]$ is the only parameter which remains to be determined. Thus, pricing an American capped call option has been reduced to the identification of $t_{e}$, which is a simple univariate optimization problem. The valuation formula for this contract is given in the next theorem. 
Theorem 1.5.12. (Valuation of American capped option with growing cap) Define

$$
t_{f} \equiv \operatorname{argmax}_{t \in[0, T]}\left\{e^{-r_{t}}\left(L_{t}-K\right)\right\} .
$$

The value of the American capped option with growing cap is given by

$$
C^{L}(S, 0)=\max _{t_{e}}\left\{C^{L}\left(t_{e}, t^{*}, t_{f}\right): t_{e} \in\left[0, t^{*} \wedge t_{f}\right]\right\}
$$

where

$$
C^{L}\left(t_{e}, t^{*}, t_{f}\right)=E^{*}\left[e^{-r\left(t_{e}-t\right)}\left\{C^{u} \mathbf{1}_{\left\{S_{t_{e}}>L_{t_{e}}\right\}}+C^{d} \mathbf{1}_{\left\{S_{t_{e}} \leq L_{t_{e}}\right\}}\right\} \mid \mathcal{F}_{t}\right] .
$$

and $C^{u}$ and $C^{d}$ are the values at time $t_{e}$ in the events $\left\{S_{t_{e}}>L_{\left.t_{e}\right\}}\right.$ and $\left\{S_{t_{e}} \leq L_{t_{e}}\right\}$, respectively.

Explicit formulas for $C^{u}$ and $C^{d}$ are given in [Broadie and Detemple [1995]].

\subsubsection{Capped Options on Nondividend-Paying Assets with Stochastic Volatility}

In this subsection we consider a fairly general class of American capped options written on nondividend-paying assets with stochastic volatility. The underlying asset price $S$ satisfies (under the $Q$-measure)

$$
d S_{t}=S_{t}\left(r d t+\sigma_{t} d \tilde{z}_{t}\right), t \in[0, T] ; S_{0} \text { given }
$$

The volatility process $\sigma \equiv\left\{\sigma_{t}, \mathcal{F}_{t}: t \in[0, T]\right\}$ is a progressively measurable, bounded above and bounded away from zero (P-a.s.). The interest rate $r$ is constant and nonnegative.

The capped call option under consideration has a payoff $(S \wedge L-K)^{+}$, where $L$ satisfies

$$
d L_{t}=L_{t} g_{t} d t, t \in[0, T], L_{0} \text { given } .
$$

We assume that the growth rate of the cap, $g$, is a progressively measurable process such that $L_{t}>K$ for all $t \in[0, T]$ and which satisfies the condition

$$
\left(g_{t}-r\right) L_{t}+r K<0, t \in[0, T] .
$$

The model (1.5.17)-(1.5.19) for the underlying asset price and for the cap is relatively general. It allows for a stochastic volatility of the underlying asset price as well as a stochastic growth rate of the cap. The factor 
underlying the stochastic behavior of the volatility and the cap is the same Brownian motion which affects the stock price. Hence, the model remains one of complete markets. The cap's growth rate may take positive as well as negative values as long as condition (1.5.19) is satisfied. This condition is a restriction on the growth rate of the cap which is clearly satisfied if the cap is constant or decreasing. It is satisfied even when the growth rate of the cap is positive as long as it is not too large.

For this model we have the following result.

Theorem 1.5.13. Consider an American capped call option with stochastic cap given by (1.5.18)-(1.5.19) when the interest rate is constant and the underlying asset price satisfies (1.5.17). The optimal exercise boundary is $B^{L}=L$. If $S \geq L$ immediate exercise is optimal and $C^{L}(S, t)=L-K$. If $S<L$ the optimal exercise policy is described by the stopping time $\tau_{L}$ where $\tau_{L} \equiv \inf \left\{v \in[t, T]: S_{v}=L_{v}\right\}$, or $\tau_{L} \equiv T$ if no such time exists. For $S<L$ and for all $t \in[0, T]$, the value of the capped option is

$C^{L}(S, t)=E^{*}\left[e^{-r\left(\tau_{L}-t\right)}\left(L_{\tau_{L}}-K\right) \mathbf{1}_{\left\{\tau_{L}<T\right\}} \mid \mathcal{F}_{t}\right]+E^{*}\left[e^{-r(T-t)}\left(S_{T}-K\right)^{+} \mathbf{1}_{\left\{\tau_{L} \geq T\right\}} \mid \mathcal{F}_{t}\right]$.

Proof of Theorem 1.5.13. We must show the optimality of stopping at the first hitting time of the cap. The valuation formula (1.5.20) is the value under that exercise policy.

(i) Suppose first that $S<L$ and assume that immediate exercise is optimal. Consider the investment strategy described below along with the exercise policy $\tau_{L}$ defined in the theorem

\begin{tabular}{rccc} 
& Time $t$ & Time $\tau_{L}<T$ & Time $\tau_{L} \geq T$ \\
Buy call & $-C(S, t)$ & $L_{\tau_{L}}-K$ & $\left(S_{T}-K\right)^{+}$ \\
Sell stock & $+S$ & $-S \tau_{L}$ & $-S_{T}$ \\
Invest $K$ & $-K$ & $K e^{r \tau_{L}}$ & $K e^{r(T-t)}$ \\
\hline Total & 0 & $K\left(e^{r \tau_{L}}-1\right)$ & $-S_{T} \mathbf{1}_{\left\{S_{T}<K\right\}}$ \\
& & & $+K\left(e^{r(T-t)}-\mathbf{1}_{\left\{S_{T} \geq K\right\}}\right)$
\end{tabular}

Since the payoff on the event $\tau_{L} \geq T$ is bounded below by

$$
-K \mathbf{1}_{\left\{S_{T}<K\right\}}+K\left(e^{r(T-t)}-\mathbf{1}_{\left\{S_{T} \geq K\right\}}\right)=K\left(e^{r(T-t)}-1\right)
$$

and since $r>0$ the strategy outlined is an arbitrage strategy. The absence of arbitrage opportunities in equilibrium implies that immediate exercise is a suboptimal strategy. 
(ii) Consider now the case $S \geq L$. By Itô's lemma the discounted payoff $\psi_{t} \equiv e^{-r t}\left(L_{t}-K\right)$ satisfies

$$
d \psi_{t}=\left(\left(g_{t}-r\right) e^{-r t} L_{t}+r e^{-r t} K\right) d t, t \in[0, T] .
$$

Condition (1.5.19) implies that the process $\psi$ is nonincreasing (P-a.s.). The optimality of immediate exercise follows since any waiting strategy leads to a decrease in the discounted payoff. 


\section{REFERENCES}

1. Ait-Sahlia, F., Optimal Stopping and Weak Convergence Methods for some Problems in Financial Economics, Ph.D. Dissertation, Stanford University (1995).

2. Amin, K., and A. Khanna, Convergence of American Option Values from Discreteto Continuous-Time Financial Models, Mathematical Finance 4 (1994), 289-304.

3. Bachelier, L., Théorie de la Spéculation., Annales de l'École Normale Supérieure 17 (1900), 21-86; in Paul H. Cottner (ed.), The Random Character of Stock Market Prices, The MIT Press, Cambridge, Mass., 1964.

4. Barles, G., J. Burdeau, M. Romano, and N. Samsaen, Critical Stock Price Near Expiration, Mathematical Finance 5 (1995), 77-95.

5. Bensoussan, A., On the Theory of Option Pricing, Acta Applicandae Mathematicae 2 (1984), 139-158.

6. Black, F., and M. Scholes, The Pricing of Options and Corporate Liabilities, Journal of Political Economy 81 (1973), 637-659.

7. Boyle, P.P., and S.M. Turnbull, Pricing and Hedging Capped Options, Journal of Futures Markets 9 (1989), 41-54.

8. Brennan, M., and E. Schwartz, The Valuation of American Put Options, Journal of Finance $\mathbf{3 2}$ (1977), 449-462.

9. L Finite Difference Methods and Jump Processes Arising in the Pricing of Contingent Claims: A Synthesis, Journal of Financial and Quantitative Analysis 13 (1978), 461-474.

10. Broadie, M., and J.B. Detemple, American Capped Call Options on DividendPaying Assets, The Review of Financial Studies 8 (1995), 161-191.

11. - American Option Valuation: New Bounds, Approximations, and a Comparison of Existing Methods, Working Paper, Columbia University, The Review of Financial Studies (1994a) (to appear).

12. Columbia University (1994b).

13. Carr, P., and R. Jarrow, The Stop-Loss Start-Gain Paradox and Option Valuation: A New Decomposition into Intrinsic and Time Value, The Review of Financial Studies 3 (1990), 469-492.

14. Carr, P., R. Jarrow, and R. Myneni, Alternative Characterizations of American Put Options, Mathematical Finance 2 (1992), 87-106.

15. Chesney, M., R.J. Elliott, and R. Gibson, Analytical Solutions for the Pricing of American Bond and Yield Options, Mathematical Finance 3 (1993), 277-294.

16. Cox, J., and S. Ross, The Valuation of Options for Alternative Stochastic Processes, Journal of Financial Economics 3 (1976), 145-166.

17. Cox, J.C., S.A. Ross, and M. Rubinstein, Option Pricing: A Simplified Approach, Journal of Financial Economics 7 (1979), 229-263.

18. Cox, J., and M. Rubinstein, Option Markets, Prentice Hall, Englewood Cliffs, New Jersey, 1985.

19. Duffie, D., Stochastic Equilibria: Existence, Spanning Number and the 'No Expected Gains from Trade' Hypothesis, Econometrica 54 (1986), 1161-1183.

20. Duffie, D., An Extension of the Black-Scholes Model of Security Valuation, Journal of Economic Theory 46 (1988), 194-204.

21. El Karoui, N., Les Aspects Probabilistes du Controle Stochastique, Lecture Notes in Mathematics 876, Springer-Verlag, Berlin, 1981, pp. 73-238.

22. El Karoui, N., and I. Karatzas, A New Approach to the Skorohod Problem and its Applications, Stochastics and Stochastics Reports 34 (1991), 57-82. 
23. Flesaker, B., The Design and Valuation of Capped Stock Index Options, Working Paper, University of Illinois at Urbana-Champaign (1992).

24. Geske, R., A Note on an Analytical Valuation Formula for Unprotected American Options on Stocks with Known Dividends, Journal of Financial Economics 7 (1979), 375-380.

25. Grabbe, O., The Pricing of Call and Put Options on Foreign Exchange, Journal of International Money and Finance 2 (1983), 239-253.

26. Grundy, B., and Z. Wiener, Theory of Rational Option Pricing: II, Working Paper, Wharton School, University of Pennsylvania (1995).

27. Harrison, M., and D. Kreps, Martingales and Arbitrage in Multiperiod Security Markets, Journal of Economic Theory 20 (1979), 381-408.

28. Harrison, M., and S. Pliska, Martingales and Stochastic Integrals in the Theory of Continuous Trading, Stochastic Processes and their Applications 11 (1981), 215-260.

29. Hull, J., Options, Futures, and other Derivative Securities, Prentice Hall, Englewood Cliffs, New Jersey, 1993.

30. Jacka, S.D., Optimal Stopping and the American Put, Mathematical Finance 1 (1991), 1-14

31. Jaillet, P., D. Lamberton, and B. Lapeyre, Variational Inequalities and the Pricing of American Options, Acta Applicandae Mathematicae 21 (1990), 263-289.

32. Karatzas, I., On the Pricing of American Options, Applied Mathematics and Optimization 17 (1988), 37-60.

33. Karatzas, I., and S. Shreve, Brownian Motion and Stochastic Calculus, Springer Verlag, New York, 1988.

34. Kim, I.J., The Analytic Valuation of American Options, The Review of Financial Studies 3 (1990), 547-572.

35. McDonald, R., and M. Schroder, A Parity Result for American Options, Working Paper, Northwestern University (1990).

36. McKean, H.P., A Free Boundary Problem for the Heat Equation Arising from a Problem in Mathematical Economics, Industrial Management Review 6 (1965), 32-39.

37. Merton, R., Theory of Rational Option Pricing, Bell Journal of Economics and Management Science 4 (1973), 141-183.

38. Myneni, R., The Pricing of American Options, The Annals of Applied Probability 2 (1992), 1-23.

39. Roll, R., An Analytic Valuation Formula for Unprotected American Call Options on Stocks with Known Dividends, Journal of Financial Economics 5 (1977), 251258.

40. Rubinstein M., and E. Reiner, Breaking Down the Barriers, Risk 4 (1991), 28-35.

41. Rutkowski, M, The Early Exercise Premium Representation of Foreign Market American Options, Mathematical Finance 4 (1994), 313-325.

42. Samuelson, P.A., Rational Theory of Warrant Pricing, Industrial Management Review 6 (1965), 13-31.

43. Schwartz, E.S., The Valuation of Warrants: Implementing a New Approach, Journal of Financial Economics 4 (1977), 79-93.

44. van Moerbeke, P.L., On Optimal Stopping and Free Boundary Problems, Arch. Rational Mech. Anal. 60 (1976), 101-148.

45. Whaley, R.E., On the Valuation of American Call Options on Stocks with Known Dividends, Journal of Financial Economics 9 (1981), 207-211. 


\section{Liste des publications au CIRANO *}

Série Scientifique / Scientific Series (ISSN 1198-8177)

96s-15 American Options on Dividend-Paying Assets / Mark Broadie et Jérôme Detemple

96s-14 Numerical Methods for Pricing Derivative Securities / Mark Broadie et Jérôme Detemple

96s-13 Monitoring New Technological Developments in the Electricity Industry : An International Perspective / Louis A. Lefebvre, Élisabeth Lefebvre et Lise Préfontaine

96s-12 Model Error in Contingent Claim Models Dynamic Evaluation / Eric Jacquier et Robert Jarrow

96s-11 Mesures de la croissance de la productivité dans un cadre d'équilibre général : L'Économie du Québec entre 1978 et 1984 / Pierre Mohnen, Thijs ten Raa et Gilles Bourque

96s-10 The Efficiency of Collective Bargaining in Public Schools / Daniel S. Hosken et David N. Margolis

96s-09 Constant Consumption and the Economic Depreciation of Natural Capital : The NonAutonomous Case / John M. Hartwick et Ngo Van Long

96s-08 Upstream-Downstream Specialization by Integrated Firms in a Partially Integrated Industry / Gérard Gaudet, Ngo Van Long et Antoine Soubeyran

96s-07 Toward a Political Theory of Environmental Policy / Marcel Boyer et Jean-Jacques Laffont

96s-06 Work Sharing and Producrivity : Evidence from a Natural Experiment / Paul Lanoie, François Raymond et Bruce Shearer

96s-05 Claims Reporting and Risk Bearing Moral Hazard in Workers' Compensation : The Canadian Context / Guylaine Baril et Paul Lanoie

96s-04 The Determinants of University Dropouts : A Sequential Decision Model with Selectivity Bias / Claude Montmarquette, Sophie Mahseredjian et Rachel Houle

96s-03 Solutions au stress financier : Un survol de la littérature / Jocelyn Martel

96s-02 The Politics and Regulation of Hydroelectricity : The Case of Quebec in the Thirties / Ruth Dupré, Michel Patry et Patrick Joly

96s-01 Cognition in Seemingly Riskless Choices and Judgments / Louis Lévy-Garboua et Claude Montmarquette

95s-51 Entry Blockading Locations / Marcel Boyer, Philippe Mahenc et Michel Moreaux

95s-50 Environmental Protection, Producer Insolvency and Lender Liability / Marcel Boyer et Jean-Jacques Laffont

95s-49 Stochastic Volatility / Eric Ghysels, Andrew Harvey et Eric Renault

95s-48 Is Workers' Compensation Disguised Unemployment Insurance? / Bernard Fortin, Paul Lanoie et Christine Laporte

95s-47 Asset and Commodity Prices with Multiattribute Durable Goods / Jérôme Detemple et Christos I. Giannikos

95s-46 Cohort Effects and Returns to Seniority in France / David N. Margolis

* Vous pouvez consulter la liste complète des publications du CIRANO et les publications elles-mêmes sur notre site World Wide Web à l'adresse suivante :

http://www.cirano.umontreal.ca/publication/page1.html 